Sharif University of Technology
Scientia Iranica
Transactions E: Industrial Engineering
hCIENTIA

Research Note

\title{
What can fuzziness do for capability analysis based on fuzzy data
}

\author{
S.M. Chen* and T.M. Hung \\ Department of Mathematics, Fu-Jen Catholic University, No. 510, Zhongzheng Rd., Xinzhuang Dist., New Taipei City 24205, \\ Taiwan, R.O.C.
}

Received 26 October 2018; received in revised form 29 April 2019; accepted 12 October 2019

\author{
KEYWORDS \\ Fuzzy set; \\ Lower membership \\ function; \\ Upper membership \\ function; \\ Process incapability \\ index.
}

\begin{abstract}
One advantage of process incapability index over the classical process capability index is that it provides uncontaminated separation between process accuracy and process precision. However, the value of the index is difficult to determine accurately when process parameters cannot be determined precisely. In such a case, fuzzy set theory can be applied to obtain more flexible and sensitive information. In this paper, a fuzzy process incapability index is proposed when the specification limits are assumed to be type2 fuzzy. When the process mean and variance are unknown and when the observations are measured imprecisely, three fuzzy estimators are considered. A simulation study is conducted based on the Thin-Film-Transistor Liquid-Crystal Display (TFT-LCD) fuzzy process. By applying the total integral value method to the membership function of a fuzzy index, it becomes easier to make a comparison of the quality of different processes.
\end{abstract}

(C) 2021 Sharif University of Technology. All rights reserved.

\section{Introduction}

A product is always categorized as "satisfied" or "unsatisfied" when assessing its quality. For example, in the educational field, pass or fail is given when the performance of a senior student is evaluated. However, does one point less than the passing grade really mean the student failed and should spend one more year on campus? The fallacy of the "binary quality" criterion in this example is clear. Further to this, we regularly face uncertainty or ambiguity in our daily life and run into some information that is difficult to describe

\footnotetext{
* Corresponding author. Tel.: 011-886-2-2905-2451;

Fax: 011-886-2-2904-4509

E-mail addresses: smchen@math.fju.edu.tw;

smchen@math.ncu.edu.twand019688@mail.fju.edu.tw

(S.M.Chen); tzminghung@gmail.com (T.M.Hung)
}

doi: $10.24200 /$ sci. 2019.52104 .2537 or interpret accurately. It is known that inferential statistics are used to analyze data when uncertainty is random. Nevertheless, non-random types of uncertainties, e.g., those caused by incomplete information, by partial information, or by vague description, do exist, but are not discussed in traditional statistical theory. Zadeh [1] introduced the fuzzy logic method officially that provided more information in such a situation after quantum philosopher Black [2] and led data analysis to a new era. For example, Rabieha et al. [3] applied the robust-fuzzy model to the automobile industry. In general, signature recognition, facial recognition, medical device like blood pressure monitor, plat number recognition via speed photography, or even debate in the court house are applications in reality where fuzzy theory can be applied.

Among all the known techniques for capability analysis, process (in) capability index provides numerical measures on whether a process conforms to the 
expected manufacturing capability. There have been many indices invented in the past few decades, and one can point to a number of such instances as capability index $C_{p}, C_{p k}$ [4], $C_{p m}$ [5], and $C_{p m k}$ [6], which are the particular cases of $C_{p}(u, v)$ [7]. Greenwich and JahrSchaffrath [8] proposed the incapability index $C_{p p}$, which provided distinct information about the process accuracy and precision. In 1998, backed by a finding that the index $C_{p p}$ may reflect process potential and performance inaccurately, Chen [9] further improved the index by modifying $C_{p p}$ to obtain the incapability index $C_{p p}^{\prime \prime}$

For the fuzzy indices in the existing literatures, all the papers published before 2017 were about the classical type-1 fuzzy process (in) capability index in which membership functions were certain. However, type1 fuzzy logic may be unable to model and minimize the effect of uncertainties. Meanwhile, it is possible that the exact membership function of a fuzzy set may not be easy, or even possible, to decide. Zadeh [10] introduced the idea of type- 2 fuzzy, which assumes that type- 1 fuzzy sets include the membership grades of type-1 fuzzy. In 2017, Parchami et al. [11] applied the concept of type-2 fuzzy to process capability indices $C_{p}$, $C_{p k}$, and $C_{p m}$ based on crisp data. In this research, due to the merit of process incapability index, an interval type-2 fuzzy process incapability index $\widetilde{\widetilde{C_{p p}^{\prime \prime}}}$ is proposed.

The rest of this paper is organized in the following: in Section 2, a brief literature review is given. In Section 3, a fuzzy incapability index is defined. In Section 4 , three fuzzy estimators of the fuzzy index are considered. In Section 5, a simulation study is studied. Section 6 presents discussion and conclusions.

\section{Literature review}

The application of fuzzy theory to capability analysis has been discussed extensively in the past decades. Given that the specification limits were triangular fuzzy, Parchami et al. [12] proposed fuzzy process capability indices $\widetilde{C_{p}}, \widetilde{C_{p k}}, \widetilde{C_{p m}}, \widetilde{C_{p m k}}$, and $\widetilde{C_{p}(u, v)}$ and discussed the relationship among them. Under the same assumption on the specification limits, Parchami et al. [13] determined confidence interval value for fuzzy process capability index $\widetilde{C_{p}}$. Moeti et al. [14] revised the work of Parchami et al. [12] in the general case by assuming that the specifications were L-R fuzzy intervals. In 2008, Parchami et al. [15] discussed the consistency of the confidence interval proposed in [12]. In 2009, Parchami and Mashinchi [16] conducted a test for the fuzzy process capability index $\widetilde{C_{p}}$. If the process mean and variance were fuzzy and, yet, the specification limits were crisp, Wu [17] investigated the decision-making on the testing process performance with fuzzy data for the index $C_{p k}$. Hsu et al. [18] used capability index $C_{p m}$ and fuzzy quality data for supplier selection. Chen et al. [19] discussed the fuzzy index $\widetilde{C_{p m}}$ with fuzzy data in 2010. In the same year, $\mathrm{Wu}$ and Liao [20] delved into the process yield by fuzzy lower confidence bounds of the index $S_{p k}$. Abdolshah et al. [21] discussed the index $C_{p m k}$ by assuming that the process mean and variance were both type- 1 fuzzy based on fuzzy data and compared them with other indices. A review of fuzzy process capability indices was given by Abdolshah [22] in 2012. Yen [23] discussed the one-sided fuzzy test for the indices $C_{p l}$ and $C_{p u}$ in 2012. Parchami et al. [24] proposed a new generation of process capability indices based on fuzzy measurements, where linear and exponentially fuzzy specification limits were discussed. Basu et al. [25] discussed an experimental design in the soap manufacturing to optimize the fuzzified process capability index where the data were collected in the languished form. Fayyaz et al. [26] investigated both univariate and multivariate fuzzy indices. Abdolshah [27] investigated loss-based process capability indices $L_{e}$ and $L_{e}^{\prime \prime}$ by employing fuzzy logic. Geng et al. [28] estimated $C_{p}$ and $C_{p k}$ based on kernel function and fuzzy analysis hierarchy process. Kaya [29] conducted an overview of the fuzzy sets on the process capability analysis.

There are relatively fewer papers that have addressed the fuzzy aspect of the incapability index $C_{p p}$, proposed by Greenwich and Jahr-Schaffrath [8] in 1995. In 2010, Wu and Liao [20] evaluated the process performance based on $C_{p p}$ for measurements with uncertainty. They assumed that the process mean and the process variance were fuzzy, but the specification limits and target were crisp. In 2012, Kaya and Baraçli [30] discussed the case in which process mean, variance, specification limits, and target were all assumed to be fuzzy. In 2014, Kaya [31] discussed the process incapability index under fuzziness with an application to decision-making.

There are even fewer papers about the fuzziness of the incapability index $C_{p p}^{\prime \prime}$ than about $C_{p p}$. In 2012, Kaya and Baraçli [30] discussed a situation when the process mean, process variance, specification limits, and target were all assumed fuzzy. Abbasi and Sadeghpour Gildeh [32] applied fuzzy critical value to the hypothesis testing problem by assuming that both process mean and variance were fuzzy; however, the specification limits and the target were fixed.

\section{Type-2 fuzzy process incapability index $\widetilde{\widetilde{C_{p p}^{\prime \prime}}}$}

Consider a process with mean $\mu$ and variance $\sigma^{2}$. Let $T$ be the target value and LSL and USL be the Lower and Upper Specification Limits, respectively. In 1995, Greenwich and Jahr-Schaffrath [8] proposed the incapability index: 


$$
C_{p p}=\frac{(\mu-\mathrm{T})^{2}+\sigma^{2}}{(\min \{\mathrm{T}-\mathrm{LSL}, \mathrm{USL}-\mathrm{T}\} / 3)^{2}}
$$

which can distinguish the inaccuracy and imprecision of a process separately. Given that $C_{p p}$ may inconsistently measure process capability, in 1998, Chen [9] proposed another incapability index $C_{p p}^{\prime \prime}$ as follows:

$$
\begin{aligned}
C_{p p}^{\prime \prime}= & \frac{\left[\max \left\{(\mu-\mathrm{T}) \frac{(\mathrm{USL}-\mathrm{LSL})}{2(\mathrm{USL}-\mathrm{T})},(\mathrm{T}-\mu) \frac{(\mathrm{USL}-\mathrm{LSL})}{2(\mathrm{~T}-\mathrm{LSL})}\right\}\right]^{2}}{\left(\frac{1}{3} \min \{\mathrm{T}-\mathrm{LSL}, \mathrm{USL}-\mathrm{T}\}\right)^{2}} \\
& +\frac{\sigma^{2}}{\left(\frac{1}{3} \min \{\mathrm{T}-\mathrm{LSL}, \mathrm{USL}-\mathrm{T}\}\right)^{2}} \triangleq C_{i a}^{\prime \prime}+C_{i p},
\end{aligned}
$$

where $C_{i a}^{\prime \prime}$ and $C_{i p}$ measure the inaccuracy and imprecision of the process. When the target is at the midpoint of the specification limits, then $C_{p p}^{\prime \prime}=C_{p p}$.

Since uncertainty may exist in the membership function of a fuzzy set, it is not realistic to use a model with precise or certain parameters. An interval type2 fuzzy process incapability index $\widetilde{\widetilde{C_{p p}^{\prime \prime}}}$ will be defined in Section 3 by assuming that the Specification Limits of the quality characteristic are type- 2 fuzzy, but the target is crisp.

Of note, the type- 2 trapezoidal membership functions of the lower and upper specification limits are denoted by $\widetilde{\widetilde{\mathrm{LSL}}}=\operatorname{TRFN}\left(u_{1}, l_{1}, u_{2}, l_{2}\right)$ and $\widetilde{\widetilde{\mathrm{USL}}}=$ $\operatorname{TRFN}\left(l_{3}, u_{3}, l_{4}, u_{4}\right)$, respectively. Then, the $\alpha$-cuts of the specification limits are

$$
\begin{aligned}
& \widetilde{\mathrm{LSL}}[\alpha]=\left[l_{1}+\alpha\left(l_{2}-l_{1}\right), u_{1}+\alpha\left(u_{2}-u_{1}\right)\right] \quad \text { and } \\
& \widetilde{\mathrm{USL}}[\alpha]=\left[l_{4}-\alpha\left(l_{4}-l_{3}\right), u_{4}-\alpha\left(u_{4}-u_{3}\right)\right] .
\end{aligned}
$$

To facilitate the computation, these $\alpha$-cuts are integrated and the fuzzy number of the specification limits is obtained as follows:

$$
\begin{aligned}
\widetilde{\widetilde{\mathrm{USL}}}= & {\left[\int_{0}^{1}\left\{\left(l_{4}-\alpha\left(l_{4}-l_{3}\right)\right)\right\} d \alpha,\right.} \\
& \left.\int_{0}^{1}\left\{\left(u_{4}-\alpha\left(u_{4}-u_{3}\right)\right)\right\} d \alpha\right] \\
& =\left[\frac{l_{4}+l_{3}}{2}, \frac{u_{4}+u_{3}}{2}\right] \triangleq\left[U_{1}, U_{2}\right], \\
\widetilde{\widetilde{\mathrm{LS}}}= & {\left[\int_{0}^{1}\left\{u_{1}+\alpha\left(u_{2}-u_{1}\right)\right\} d \alpha,\right.} \\
& \left.\int_{0}^{1}\left\{l_{1}+\alpha\left(l_{2}-l_{1}\right)\right\} d \alpha\right] \\
= & {\left[\frac{u_{1}+u_{2}}{2}, \frac{l_{1}+l_{2}}{2}\right] \triangleq\left[L_{1}, L_{2}\right] . }
\end{aligned}
$$

A fuzzy incapability index $\widetilde{\widetilde{C_{p p}^{\prime \prime}}}$ is defined as:

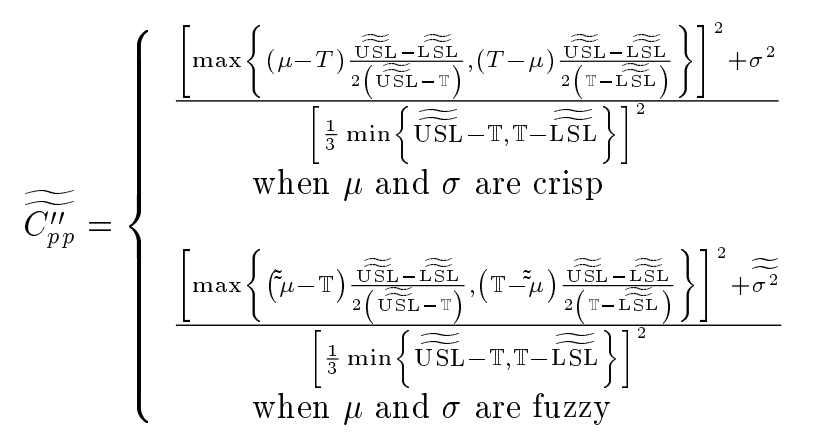

where $\mathbb{T}=[T, T], \tilde{\tilde{\mu}}$, and $\widetilde{\widetilde{\sigma^{2}}}$ are type-2 fuzzy numbers of $\mu$ and $\sigma^{2}$, respectively.

Remark 1. The expression above is presented only for convenience. It is clear that an interval should not be put on the denominator from the mathematical point of view. To conduct the computation, for those terms with an interval expression in the denominator, the left end point of each case must be divided by the right end point of the denominator and the right end point is derived by dividing the numerator by the left end point of the denominator.

Notice that since $\min \{a, b\}=\frac{a+b}{2}-\frac{|a-b|}{2}$, the common denominator can be written as follows:

$$
\begin{aligned}
& \frac{1}{3} \min \{\mathrm{T}-\widetilde{\widetilde{\mathrm{LSL}}}, \widetilde{\widetilde{\mathrm{USL}}}-\mathrm{T}\} \\
& \quad=\frac{1}{3}\left\{\frac{\widetilde{\widetilde{\mathrm{USL}}}-\widetilde{\widetilde{\mathrm{LSL}}}}{2}-\frac{|\widetilde{\widetilde{\mathrm{USL}}}+\widetilde{\widetilde{\mathrm{LSL}}}-2 \mathrm{~T}|}{2}\right\} .
\end{aligned}
$$

Therefore, the index $\widetilde{\widetilde{C_{p p}^{\prime \prime}}}$ is a function of the difference and the sum of the specification limits. Based on the intersection of interval type-2 fuzzy upper and lower specification limits ([11], see Figure 1), the difference between and the sum of interval type-2 fuzzy specification limits are defined in the following:

$$
\begin{aligned}
& \widetilde{\widetilde{\mathrm{USL}}}-\widetilde{\widetilde{\mathrm{LSL}}}=\widetilde{\widetilde{\mathrm{USL}}}-\widetilde{\widetilde{\mathrm{LSL}}} \triangleq\left[D_{i f, 1}, D_{i f, 2}\right] \\
& =\left[\frac{l_{4}+l_{3}-l_{2}-l_{1}}{2}, \frac{u_{4}+u_{3}-u_{2}-u_{1}}{2}\right], \\
& \widetilde{\widetilde{\mathrm{LSL}}}+\widetilde{\widetilde{\mathrm{USL}}}=\widetilde{\widetilde{\mathrm{LSL}}} \oplus \widetilde{\widetilde{\mathrm{USL}}} \triangleq\left[S_{u m, 1}, S_{u m, 2}\right] \\
& =\left[\min \left\{\frac{\mathrm{l}_{4}+\mathrm{l}_{3}+\mathrm{l}_{2}+\mathrm{l}_{1}}{2}, \frac{\mathrm{u}_{4}+\mathrm{u}_{3}+\mathrm{u}_{2}+\mathrm{u}_{1}}{2}\right\},\right. \\
& \left.\max \left\{\frac{\mathrm{l}_{4}+\mathrm{l}_{3}+\mathrm{l}_{2}+\mathrm{l}_{1}}{2}, \frac{\mathrm{u}_{4}+\mathrm{u}_{3}+\mathrm{u}_{2}+\mathrm{u}_{1}}{2}\right\}\right] .
\end{aligned}
$$




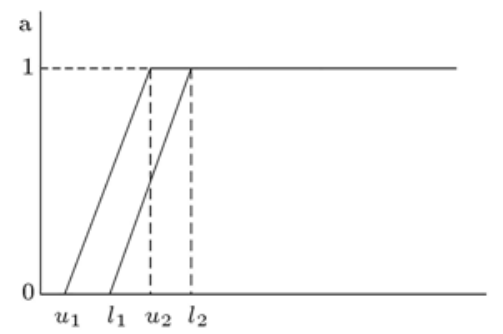

(a)

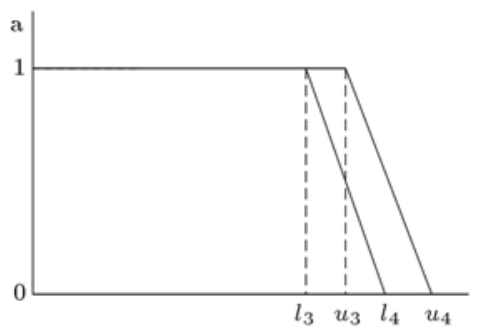

(b)

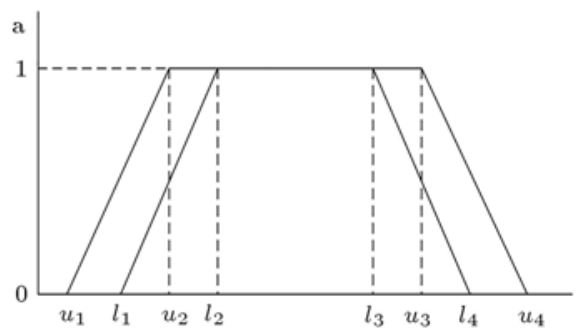

(c)

Figure 1. Membership function of (a) type-2 fuzzy lower specification limit, (b) type-2 fuzzy upper specification limit, and (c) intersection of Interval type-2 fuzzy specification limits.

From the geometrical point of view, the end points of the difference $\widetilde{\widetilde{\mathrm{USL}}} \odot \widetilde{\widetilde{\mathrm{LSL}}}$ correspond to the area bound by the inner trapezoidal and the outer trapezoidal. On the other hand, consider two lines $L_{1}$ and $L_{2}$ where $L_{1}$ passes through the points $\left(l_{1}, 0\right),\left(l_{2}, 1\right)$ and $L_{2}$ passes through the points $\left(l_{4}, 0\right),\left(l_{3}, 1\right)$. If the slopes of these two lines have the same absolute value, then the end points of the sum $\widetilde{\widetilde{\mathrm{LSL}}} \oplus \widetilde{\widetilde{\mathrm{USL}}}$ of the specification limits correspond to the area of the trapezoidal with four vertices at $(0,0),(0,1),\left(l_{1}+l_{4}, 0\right)$, and $\left(l_{2}+l_{3}, 1\right)$ and to the area of the trapezoidal with four vertices at $(0,0)$, $(0,1),\left(u_{1}+u_{4}, 0\right)$, and $\left(u_{2}+u_{3}, 1\right)$, respectively.

Hence, the common denominator can be rewritten as follows:

$$
\begin{aligned}
& \frac{1}{3} \min \{\mathrm{T}-\widetilde{\widetilde{\mathrm{LSL}}}, \widetilde{\widetilde{\mathrm{USL}}}-\mathrm{T}\} \\
& \quad=\frac{1}{3}\left\{\frac{\widetilde{\widetilde{\mathrm{USL}}}-\widetilde{\widetilde{\mathrm{LSL}}}}{2}-\frac{|\widetilde{\mathrm{USL}}+\widetilde{\widetilde{\mathrm{LSL}}}-2 \mathrm{~T}|}{2}\right\} \\
& \quad=\left[\frac{D_{i f, 1}-\left|S_{u m, 2}-2 \mathrm{~T}\right|}{6}, \frac{D_{i f, 2}-\left|S_{u m, 1}-2 \mathrm{~T}\right|}{6}\right] \\
& \quad \triangleq\left[D_{L}, D_{R}\right] .
\end{aligned}
$$

\section{Fuzzy estimators of $\widetilde{\widetilde{\mathrm{C}^{\prime \prime}}}$}

The fuzzy incapability index $\widetilde{\widehat{C_{p p}^{\prime \prime}}}$ is a function of process mean $\mu$ and process variance $\sigma^{2}$; when parameters $\mu$ and $\sigma^{2}$ are unknown, they must be estimated before conducting any further study. On the other hand, in reality, since continuous characteristics may not be easy to observe precisely, the collected data are basically fuzzy. One can point to Viertl [33] for further reference on fuzzy data. Examples for fuzzy data can be found in the studies of Filzmoser and Viertl [34], Wu [17], Chen et al. [19], and other corresponding references. Denote:

$$
\widetilde{X_{1}}=\left[\mathrm{X}_{1}^{\mathrm{L}}, \mathrm{X}_{1}^{\mathrm{R}}\right], \widetilde{X_{2}}=\left[\mathrm{X}_{2}^{\mathrm{L}}, \mathrm{X}_{2}^{\mathrm{R}}\right], \ldots, \widetilde{X_{n}}=\left[\mathrm{X}_{\mathrm{n}}^{\mathrm{L}}, \mathrm{X}_{\mathrm{n}}^{\mathrm{R}}\right],
$$

$$
\mathrm{X}_{\mathrm{i}}^{\mathrm{L}}<\mathrm{X}_{\mathrm{i}}^{\mathrm{R}}
$$

as a fuzzy sample of size $n$ from a normal distribution $N\left(\mu, \sigma^{2}\right)$. For the concept of normality for fuzzy random variables, the reader is referred to Puri and Ralescu [35] as well as Kaya and Kahraman [36]. Define the fuzzy sample $\widetilde{\bar{X}}=\left[\frac{\sum_{i=1}^{n} X_{i}^{L}}{n}, \frac{\sum_{i=1}^{n} X_{i}^{R}}{n}\right] \triangleq\left[\bar{X}^{L}, \bar{X}^{R}\right]$ mean $\widetilde{\bar{X}}=\left[\frac{\sum_{i=1}^{n} X_{i}^{L}}{n}, \frac{\sum_{i=1}^{n} X_{i}^{R}}{n}\right] \triangleq\left[\bar{X}^{L}, \bar{X}^{R}\right]$ and the fuzzy sample variance:

$$
\begin{aligned}
\widetilde{\mathrm{S}^{2}} & =\left[\min \left\{\frac{\sum_{\mathrm{i}=1}^{\mathrm{n}}\left(\mathrm{X}_{\mathrm{i}}^{\mathrm{L}}-\overline{\mathrm{X}}^{\mathrm{L}}\right)^{2}}{\mathrm{n}-1}, \frac{\sum_{\mathrm{i}=1}^{\mathrm{n}}\left(\mathrm{X}_{\mathrm{i}}^{\mathrm{R}}-\overline{\mathrm{X}}^{\mathrm{R}}\right)^{2}}{\mathrm{n}-1}\right\},\right. \\
& \left.\max \left\{\frac{\sum_{\mathrm{i}=1}^{\mathrm{n}}\left(\mathrm{X}_{\mathrm{i}}^{\mathrm{L}}-\overline{\mathrm{X}}^{\mathrm{L}}\right)^{2}}{\mathrm{n}-1}, \frac{\sum_{\mathrm{i}=1}^{\mathrm{n}}\left(\mathrm{X}_{\mathrm{i}}^{\mathrm{R}}-\overline{\mathrm{X}}^{\mathrm{R}}\right)^{2}}{\mathrm{n}-1}\right\}\right] \\
& \triangleq\left[\mathrm{S}_{1}^{2}, \mathrm{~S}_{2}^{2}\right] .
\end{aligned}
$$

Inspired by the unbiased estimator of $\sigma^{2}$ based on $100(1-\beta) \%$ confidence interval that was proposed by Buckley [37], an unbiased fuzzy type-2 estimator $\underset{\widetilde{\sigma_{B}^{2}}}{\widetilde{\sigma}}$ of the variance $\sigma^{2}$ is defined which has $\alpha$-cuts $\underset{\sigma_{B}^{2}}{\stackrel{B}{\approx}}[\alpha]=\left[\mathrm{S}_{\mathrm{BL}}^{2}, \mathrm{~S}_{\mathrm{BR}}^{2}\right]$, where:

$$
\begin{aligned}
& \mathrm{S}_{\mathrm{BL}}^{2} \triangleq {\left[\mathrm{S}_{\mathrm{BL} 1}^{2}, \mathrm{~S}_{\mathrm{BL} 2}^{2}\right]=\left[\frac{(\mathrm{n}-1) \cdot S_{1}^{2}}{(1-\alpha) \chi_{\beta / 2 ; n-1}^{2}+\alpha(\mathrm{n}-1)},\right.} \\
&\left.\frac{(\mathrm{n}-1) \cdot S_{2}^{2}}{(1-\alpha) \chi_{\beta / 2 ; n-1}^{2}+\alpha(\mathrm{n}-1)}\right], \\
& \mathrm{S}_{\mathrm{BR}}^{2} \triangleq\left[\mathrm{S}_{\mathrm{BR} 1}^{2}, \mathrm{~S}_{\mathrm{BR} 2}^{2}\right]=\left[\frac{(\mathrm{n}-1) \cdot S_{1}^{2}}{(1-\alpha) \chi_{1-\beta / 2 ; n-1}^{2}+\alpha(\mathrm{n}-1)},\right. \\
&\left.\frac{(\mathrm{n}-1) \cdot S_{2}^{2}}{(1-\alpha) \chi_{1-\beta / 2 ; n-1}^{2}+\alpha(\mathrm{n}-1)}\right] .
\end{aligned}
$$

For $0<\beta<1, \chi_{\beta / 2 ; n-1}^{2}\left(\chi_{1-\beta / 2 ; n-1}^{2}\right)$ is the upper (lower) $\beta / 2$ critical point of a chi-square distribution with $n-1$ degrees of freedom. 
The type-2 fuzzy estimator $\widetilde{\widetilde{\mu_{B}}}$ of the process mean $\mu$ that corresponds to $\underset{\sigma_{B}^{2}}{\approx}$, has $\alpha$-cuts $\widetilde{\widetilde{\mu_{B}}}[\alpha]=$ $\left[\widetilde{\mu_{\mathrm{BL}}}, \widetilde{\mu_{\mathrm{BR}}}\right]$ where:

$$
\begin{aligned}
\widetilde{\mu_{\mathrm{BL}}} & \triangleq\left[\mu_{\mathrm{BL} 1}, \mu_{\mathrm{BL} 2}\right]=\left[\overline{\mathrm{X}}^{\mathrm{L}}\right. \\
& \left.-\mathrm{t}_{\beta / 2 ; n-1} \frac{S_{B R 2}}{\sqrt{\mathrm{n}}}, \overline{\mathrm{X}}^{\mathrm{L}}-\mathrm{t}_{\beta / 2 ; n-1} \frac{S_{B R 1}}{\sqrt{\mathrm{n}}}\right], \\
\widetilde{\mu_{\mathrm{BR}}} & \triangleq\left[\mu_{\mathrm{BR} 1}, \mu_{\mathrm{BR} 2}\right]=\left[\overline{\mathrm{X}}^{\mathrm{R}}\right. \\
& \left.+\mathrm{t}_{\beta / 2 ; n-1} \frac{\mathrm{s}_{B L 1}}{\sqrt{\mathrm{n}}}, \overline{\mathrm{X}}^{\mathrm{R}}+\mathrm{t}_{\beta / 2 ; n-1} \frac{\mathrm{s}_{B L 2}}{\sqrt{\mathrm{n}}}\right] .
\end{aligned}
$$

In addition, $t_{\alpha / 2 ; n-1}$ is the upper $\alpha / 2$ critical point of a $t$-distribution with $n-1$ degrees of freedom.

It is well known that for a sample taken from a distribution with a finite fourth moment including $n \rightarrow \infty$, the sample variance is $S^{2} \rightarrow N\left(\sigma^{2}, \frac{\mu_{4}-\sigma^{4}}{n}\right)$, where $\mu_{4}=\mathrm{E}(\mathrm{X}-\mathrm{EX})^{4}$ [38]. Hummel et al. [39] re-expressed the results as $S^{2} \underset{L}{\rightarrow} N\left(\sigma^{2},(\gamma-1) \frac{\sigma^{4}}{n}\right)$, where $\gamma=\frac{\mu_{4}}{\sigma^{4}}$ was kurtosis. Hence, the second type- 2 fuzzy estimator of the variance, denoted by $\widetilde{\widetilde{\sigma_{N A}^{2}}}$, has $\alpha$-cuts $\widetilde{\widetilde{\sigma_{N A}^{2}}}[\alpha]=\left[\mathrm{S}_{\mathrm{NAL}}^{2}, \mathrm{~S}_{\mathrm{NAR}}^{2}\right]$, where:

$$
\begin{aligned}
\mathrm{S}_{\mathrm{NAL}}^{2} \Delta & =\left[\mathrm{S}_{\mathrm{NL} 1}^{2}, \mathrm{~S}_{\mathrm{NL} 2}^{2}\right] \\
& =\left[\frac{S_{1}^{2}}{(1-\alpha) \cdot\left(1+z_{\frac{\beta}{2}} \sqrt{\frac{\hat{\gamma}-1}{n}}\right)+\alpha},\right. \\
& \frac{S_{2}^{2}}{\mathrm{~S}_{\mathrm{NAR}}^{2} \Delta}=\left[\mathrm{S}_{\mathrm{NR} 1}^{2}, \mathrm{~S}_{\mathrm{NR} 2}^{2}\right] \\
& =\left[\frac{\alpha) \cdot\left(1+z_{\frac{\beta}{2}} \sqrt{\frac{\hat{\gamma}-1}{n}}\right)+\alpha}{(1-\alpha) \cdot\left(1-z_{\frac{\beta}{2}} \sqrt{\frac{\hat{\gamma}-1}{n}}\right)+\alpha},\right. \\
& \left.\frac{S_{2}^{2}}{(1-\alpha) \cdot\left(1-z_{\frac{\beta}{2}} \sqrt{\frac{\hat{\gamma}-1}{n}}\right)+\alpha}\right] .
\end{aligned}
$$

$\hat{\gamma}$ is an estimator of the kurtosis $\gamma$, and $z_{\beta / 2}$ is the upper $\beta / 2$ critical point of a standard normal distribution. Therefore, the type- 2 fuzzy estimator $\widetilde{\widetilde{\mu_{N A}}}$ of the mean $\mu$ corresponds to $\widehat{\widetilde{\sigma_{N A}^{2}}}$ which can be characterized by $\alpha$-cuts $\widetilde{\widetilde{\mu_{N A}}}[\alpha]=\left[\widetilde{\mu_{\mathrm{NAL}}}, \widetilde{\mu_{\mathrm{NAR}}}\right]$ where:

$$
\begin{aligned}
\widetilde{\mu_{\mathrm{NAL}}} & \triangleq\left[\mu_{\mathrm{NL} 1}, \mu_{\mathrm{NL} 2}\right] \\
& =\left[\overline{\mathrm{X}}^{\mathrm{L}}-\mathrm{z}_{\beta / 2} \frac{S_{N R 2}}{\sqrt{\mathrm{n}}}, \overline{\mathrm{X}}^{\mathrm{L}}-\mathrm{z}_{\beta / 2} \frac{S_{N R 1}}{\sqrt{\mathrm{n}}}\right], \\
\widetilde{\mu_{\mathrm{NAR}}} & \triangleq\left[\mu_{\mathrm{NR} 1}, \mu_{\mathrm{NR} 2}\right] \\
& =\left[\overline{\mathrm{X}}^{\mathrm{R}}+\mathrm{z}_{\beta / 2} \frac{\mathrm{S}_{N L 1}}{\sqrt{\mathrm{n}}}, \overline{\mathrm{X}}^{\mathrm{R}}+\mathrm{z}_{\beta / 2} \frac{\mathrm{S}_{N L 2}}{\sqrt{\mathrm{n}}}\right] .
\end{aligned}
$$

Notice that $\widetilde{\widetilde{\sigma_{N A}^{2}}}$ is well defined only when $\hat{\gamma} \geq 1$ and $(1-\alpha) \cdot\left(1 \pm z_{\beta / 2} \sqrt{\frac{\hat{\gamma}-1}{n}}\right)+\alpha>0$. This also means $\frac{-1}{1-\alpha}<z_{\beta / 2} \sqrt{\frac{\hat{\gamma}-1}{n}}<\frac{1}{1-\alpha}$ for $0 \leq \alpha \leq 1$. However, since the confidence level $1-\beta$ is usually large, it implies that $Z_{\beta / 2}$ is a large positive value. Hence, $1 \leq \hat{\gamma}<$ $\frac{n}{(1-\alpha)^{2} \cdot z_{\beta / 2}^{2}}+1$.

In a study done by Hummel et al. [39], methods used for estimating population variance were discussed for several distributions. They concluded that with absolutely no distributional assumptions, the adjusted chi-square method was recommended based on its reasonable performance and its theoretically logical extension from the traditional Chi-square method (which was the best if the underlying distribution was normal). Based on their result, one more type- 2 fuzzy estimator $\widetilde{\widetilde{\sigma_{A d f}^{2}}}$ of $\sigma^{2}$ can be defined with $\alpha$-cuts $\widetilde{\widetilde{\sigma_{A d f}^{2}}}[\alpha]=$ $\left[\mathrm{S}_{\text {AdfL }}^{2}, \mathrm{~S}_{\text {AdfR }}^{2}\right]$ where:

$$
\begin{aligned}
\mathrm{S}_{\mathrm{AdfL}}^{2} \triangleq & {\left[\mathrm{S}_{\mathrm{AdfL} 1}^{2}, \mathrm{~S}_{\mathrm{AdfL} 2}^{2}\right]=\left[\frac{\widehat{\delta} \cdot S_{1}^{2}}{(1-\alpha) \chi_{\beta / 2 ; \hat{\delta}}^{2}+\alpha \cdot \hat{\delta}},\right.} \\
& \left.\frac{\widehat{\delta} \cdot S_{2}^{2}}{(1-\alpha) \chi_{\beta / 2 ; \hat{\delta}}^{2}+\alpha \cdot \hat{\delta}}\right]
\end{aligned}
$$

$$
\mathrm{S}_{\mathrm{AdfR}}^{2} \triangleq\left[\mathrm{S}_{\mathrm{AdfR} 1}^{2}, \mathrm{~S}_{\mathrm{AdfR} 2}^{2}\right]=\left[\frac{\hat{\delta} \cdot S_{1}^{2}}{(1-\alpha) \chi_{1-\beta / 2 ; \hat{\delta}}^{2}+\alpha \cdot \hat{\delta}}\right.
$$

$$
\left.\frac{\hat{\delta} \cdot S_{2}^{2}}{(1-\alpha) \chi_{1-\beta / 2 ; \hat{\delta}}^{2}+\alpha \cdot \hat{\delta}}\right]
$$

and $\hat{\delta}=\frac{2 n}{(\hat{\gamma}-3)+\frac{2 n}{n-1}}$ is the estimated degrees of freedom. The $\alpha$-cuts of the type- 2 fuzzy estimator $\widetilde{\widetilde{\mu_{A d f}}}$ of the mean $\mu$ are $\widetilde{\mu_{\text {Adf }}}[\alpha]=\left[\widetilde{\mu_{\text {AdfL }}}, \widetilde{\mu_{\text {AdfR }}}\right]$, where:

$$
\begin{aligned}
\widetilde{\mu_{\text {AdfL }}} & \triangleq\left[\mu_{\text {AdfL } 1}, \mu_{\text {AdfL } 2}\right] \\
& =\left[\overline{\mathrm{X}}^{\mathrm{L}}-\mathrm{z}_{\beta / 2} \frac{S_{\text {Adf R2 }}}{\sqrt{\mathrm{n}}}, \overline{\mathrm{X}}^{\mathrm{L}}-\mathrm{z}_{\beta / 2} \frac{S_{\text {Adf R1 }}}{\sqrt{\mathrm{n}}}\right],
\end{aligned}
$$




$$
\begin{aligned}
\widetilde{\mu_{\text {AdfR }}} & \triangleq\left[\mu_{\text {AdfR } 1}, \mu_{\text {AdfR } 2}\right] \\
& =\left[\overline{\mathrm{X}}^{\mathrm{R}}+\mathrm{z}_{\beta / 2} \frac{S_{\text {Adf } L 1}}{\sqrt{\mathrm{n}}}, \overline{\mathrm{X}}^{\mathrm{R}}+\mathrm{t}_{\beta / 2 ; n-1} \frac{S_{\text {Adf } L 2}}{\sqrt{\mathrm{n}}}\right] .
\end{aligned}
$$

Obviously, $\mathrm{S}_{\mathrm{BL} 1}^{2} \leq \mathrm{S}_{\mathrm{BL} 2}^{2}, \mathrm{~S}_{\mathrm{BR} 1}^{2} \leq \mathrm{S}_{\mathrm{BR} 2}^{2}, \mathrm{~S}_{\mathrm{NL} 1}^{2} \leq$ $\mathrm{S}_{\mathrm{NL} 2}^{2}, \mathrm{~S}_{\mathrm{NR} 1}^{2} \leq \mathrm{S}_{\mathrm{NR} 2}^{2}$, and $\mathrm{S}_{\mathrm{AdfL} 1}^{2} \leq \mathrm{S}_{\mathrm{AdfL} 2}^{2}, \mathrm{~S}_{\mathrm{AdfR} 1}^{2} \leq$ $\mathrm{S}_{\mathrm{AdfR} 2}^{2}$. In addition, as $\alpha=1, \widehat{\widetilde{\sigma_{B}^{2}}}=\widehat{\widehat{\sigma_{N A}^{2}}}=\widehat{\widehat{\sigma_{A d f}^{2}}}=$ $\left[S_{1}^{2}, S_{2}^{2}\right]$, which reduces the type-2 fuzzy estimators to type-1 fuzzy estimators (see Figure 2: The left leg represents the membership function of $S_{1}^{2}$ and the right leg represents the membership function of $S_{2}^{2}$ ).

By substituting $\alpha$-cuts of the parameters defined above into $\widetilde{\widetilde{C_{p p}^{\prime \prime}}}$ and simplifying them using interval arithmetic, based on fuzzy data, the $\alpha$-cuts of the three estimators $\widetilde{\widetilde{C_{p p, B}^{\prime \prime}}}, \widetilde{\widetilde{C_{p p, N A}^{\prime \prime}}}$, and $\widetilde{\widetilde{C_{p p, A d f}^{\prime \prime}}}$ are defined in the equations shown in Box I. Putting these $\alpha$-cuts together, we obtain a fuzzy trapezoidal-shaped fuzzy

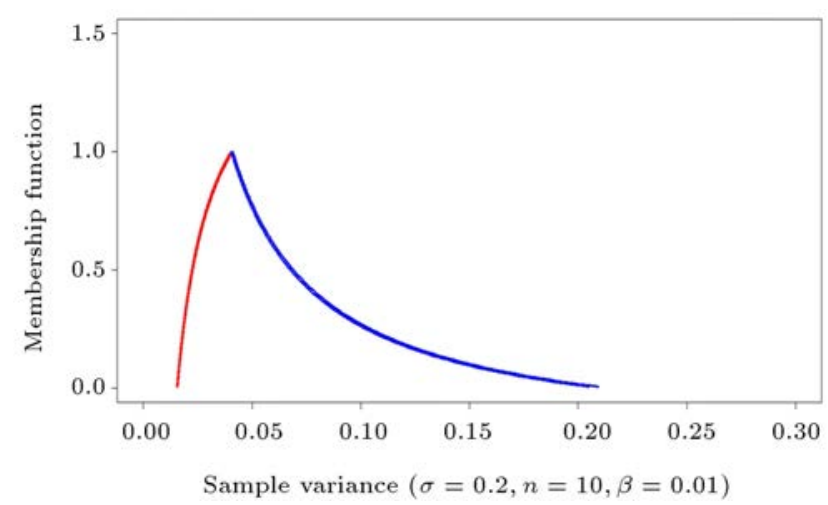

Figure 2. Membership function of fuzzy sample variance. number $\widetilde{\widetilde{C_{p p, B}^{\prime \prime}}}$. The second fuzzy index has $\alpha$-cuts as shown in Box II. Putting these $\alpha$-cuts together, a fuzzy trapezoidal-shaped fuzzy number $\widehat{C_{p p, N A}^{\prime \prime}}$ is obtained. The third fuzzy index has $\alpha$-cuts as shown in Box III. Putting these $\alpha$-cuts together, we have the third fuzzy trapezoidal-shaped fuzzy number $\widehat{\widetilde{C_{p p, A d f}^{\prime \prime}}}$.

\section{Simulation study}

To discuss the above results, an example related to a Thin-Film-Transistor Liquid-Crystal Display (TFTLCD) is provided in this section. A TFT-LCD is a variant of Liquid-Crystal Display (LCD) that uses ThinFilm-Transistor (TFT) technology to improve image quality such as addressability and contrast. TFT-LCDs are used in broad applications, for instance, mobile phones, video game systems and navigation systems, etc.

At the beginning of the TFT-LCD manufacturing process, the distance D1 between lines L1 and L2 on the first layer (see Figure 3 ) is a concern given that if D1 is too wide or too narrow, it will cause defects on the second or third layer of the TFT and the products may need to be scraped or reworked, which will lead to the conclusion that the process fails. In reality, to improve the yield for such a type of processes without affecting further progress, engineers may consider modifying the tolerance specification limits so that the process can be classified as capable. Since the optimal range of modification becomes important, fuzzy theory is, therefore, considered to study the suitable level of modification.

In 2013, Park et al. [40] proposed a new edge

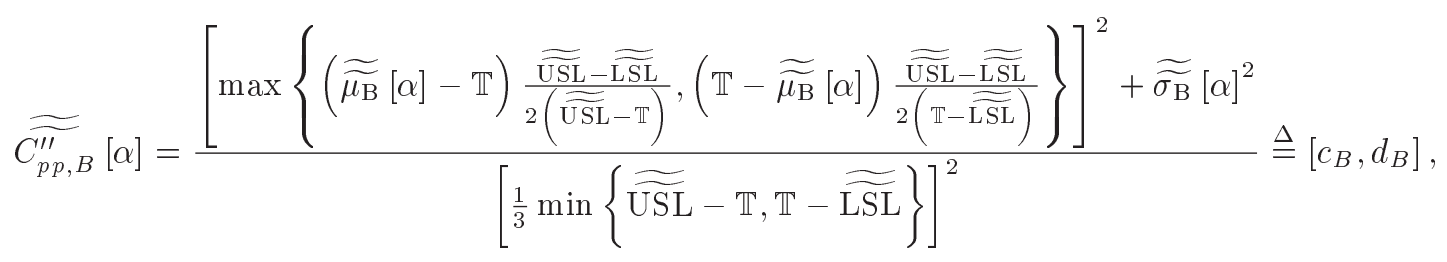

where:

$$
\begin{aligned}
& c_{B}=\frac{i, j, k, l, r, s=1,2\left\{\left[\frac{D_{i f, k} \cdot\left[\left(\mu_{\mathrm{BLi}}-T\right)\left(2 \mathrm{~T}-S_{u m, l}\right)+\left|\mu_{\mathrm{BLi}}-T\right| D_{i f, k}\right]}{4\left(\mathrm{U}_{r}-T\right)\left(T-\mathrm{L}_{s}\right)}\right]^{2}+s_{\mathrm{BLj}}^{2}\right\}}{D_{R}^{2}} \\
& \max _{B}=\frac{i, j, k, l, r, s=1,2\left\{\left[\frac{\left.\left.D_{i f, k} \cdot\left[\left(\mu_{\mathrm{BRi}}-T\right)\left(2 T-S_{u m, l}\right)+\left|\mu_{\mathrm{BRi}}-T\right| D_{i f, k}\right]\right]^{2}+s_{\mathrm{BRj}}^{2}\right\}}{4\left(\mathrm{U}_{r}-T\right)\left(T-\mathrm{L}_{s}\right)}\right.\right.}{D_{L}^{2}} .
\end{aligned}
$$




$$
\widetilde{\widetilde{C_{p p}^{\prime \prime}, N A}}[\alpha]=\frac{\left[\max \left\{\left(\widetilde{\widetilde{\mu_{\mathrm{NA}}}}[\alpha]-\mathbb{T}\right) \frac{\widetilde{\widetilde{\mathrm{USL}}}-\widetilde{\mathrm{LSL}}}{2(\widetilde{\widetilde{\mathrm{USL}}}-\mathbb{T})},\left(\mathbb{T}-\widetilde{\widetilde{\mu_{\mathrm{NA}}}}[\alpha]\right) \frac{\widetilde{\mathrm{USL}}-\widetilde{\overline{\mathrm{LSL}}}}{2(\mathbb{T}-\widetilde{\mathrm{LSL}})}\right\}\right]^{2}+\widetilde{\widetilde{\sigma_{N A}^{2}}}[\alpha]}{\left[\frac{1}{3} \min \{\widetilde{\mathrm{USL}}-\mathbb{T}, \mathbb{T}-\widetilde{\mathrm{LSL}}\}\right]^{2}} \triangleq\left[c_{N A}, d_{N A}\right],
$$

where:

$$
\begin{gathered}
c_{N A}=\frac{\min _{i, j, k, l, r, s=1,2}\left\{\left[\frac{D_{i f, k} \cdot\left[\left(\mu_{\mathrm{NLi}}-T\right)\left(2 T-S_{u m, l}\right)+\left|\mu_{\mathrm{NLi}}-T\right| D_{i f, k}\right]}{4\left(\mathrm{U}_{r}-T\right)\left(T-\mathrm{L}_{s}\right)}\right]^{2}+s_{\mathrm{NLj}}^{2}\right\}}{D_{R}^{2}}, \\
\max _{N A}=\frac{i, j, k, l, r, s=1,2\left\{\left[\frac{D_{i f, k} \cdot\left[\left(\mu_{\mathrm{NRi}}-T\right)\left(2 T-S_{u m, l}\right)+\left|\mu_{\mathrm{NRi}}-T\right| D_{i f, k}\right]}{4\left(\mathrm{U}_{r}-T\right)\left(T-\mathrm{L}_{s}\right)}\right]^{2}+s_{\mathrm{NRj}}^{2}\right\}}{D_{L}^{2}} .
\end{gathered}
$$

Box II

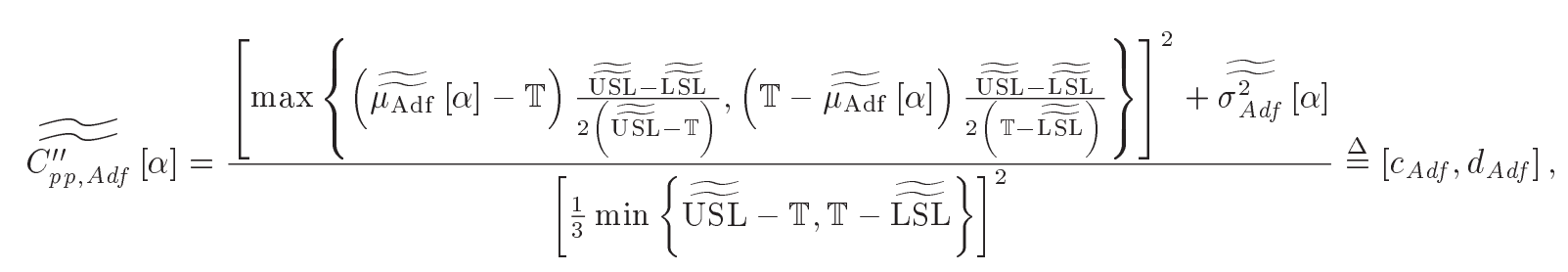

where:

$$
\begin{gathered}
c_{\text {Adf }}=\frac{\min _{i, j, k, l, r, s=1,2}\left\{\left[\frac{D_{i f, k} \cdot\left[\left(\mu_{\mathrm{AdfLi}}-T\right)\left(2 T-S_{u m, l}\right)+\left|\mu_{\mathrm{AdfLi}}-T\right| D_{i f, k}\right]}{4\left(\mathrm{U}_{r}-T\right)\left(T-\mathrm{L}_{s}\right)}\right]^{2}+\mathrm{s}_{\mathrm{AdfLj}}^{2}\right\}}{D_{R}^{2}}, \\
d_{\text {Adf }}=\frac{i, j, k, l, r, s=1,2\left\{\left[\frac{D_{i f, k} \cdot\left[\left(\mu_{\mathrm{AdfRi}}-T\right)\left(2 T-S_{u m, l}\right)+\left|\mu_{\mathrm{AdfRi}}-T\right| D_{i f, k}\right]}{4\left(\mathrm{U}_{r}-T\right)\left(T-\mathrm{L}_{s}\right)}\right]^{2}+\mathrm{s}_{\mathrm{AdfRj}}^{2}\right\}}{D_{L}^{2}} .
\end{gathered}
$$

detection algorithm which used facet model to provide more stable and accurate TFT-LCD pattern and detect the edge most reliably and precisely, compared to other algorithms. With such an algorithm, the standard deviation of measurement can be quite small. However, a company may rather adopt an algorithm with lower precision in the measurement due to certain restrictions or constraints in reality. By using the sample data given in their paper, the quality of processes with the same mean and, yet, different standard deviations will be discussed in the following via three fuzzy estimators of the fuzzy process incapability index $\widetilde{\widetilde{C_{p p}^{\prime \prime}}}$ to determine the effect of variance on the diagnosis of quality.

Assume that the mean distance D1 between L1 and L2 of the first layer in a particular TFT-LCD process is 36.5865 . If the target value is set at 36.0125 and the specification limits of LSL and USL are set at 35.65 and 37.05 , respectively, then the values of the classical incapability index $C_{p p}^{\prime \prime}$ will be $1.2541,1.2543$, $1.2549,1.2574,1.3375,1.5885,2.0065$ for $\sigma=0.002$, $0.006,0.01,0.02,0.1,0.2,0.3$, respectively. It is obvious that even though the quality is enhanced as 


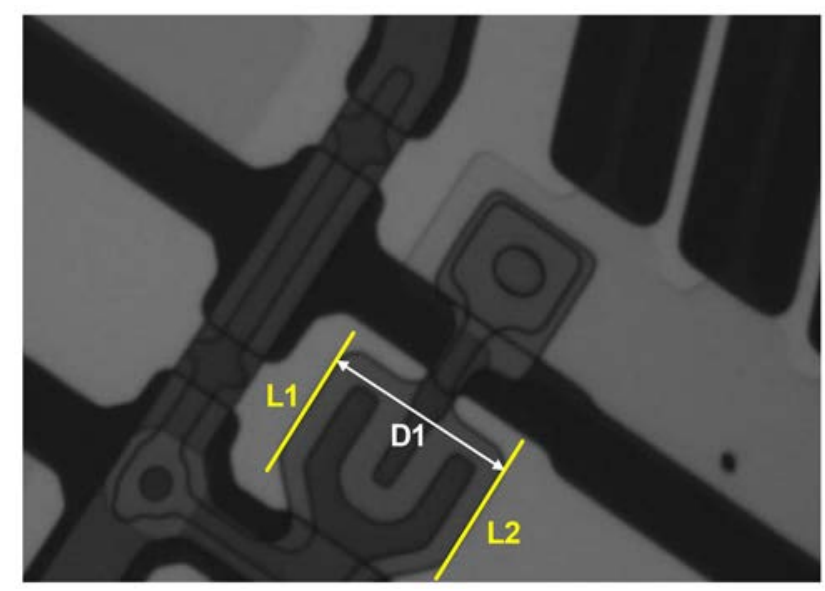

Figure 3. Distance D1 between L1 and L2 on the first layer in the Thin-Film-Transistor Liquid-Crystal Display (TFT-LCD) process.

the variability is reduced, none of the seven processes is adequate for producing products that conform to the prerequisite when the specification limits are crisp (see Table 1 [41]).

Based on some valuable information, under the condition that all the possible adjustments meet the company's requirement, the quality engineer confirms that the lower specification limit is roughly lower than 35.65 and the upper specification limit is roughly larger than 37.05. Given that type- 2 fuzzy can handle the uncertainty associated with the membership function of type-1 fuzzy, type-2 linear trapezoidal fuzzy specification limits are considered and set at:

$$
\begin{aligned}
& \widetilde{\widetilde{\mathrm{USL}}}=\operatorname{TRFN}(37.05,38.85,40.85,40.90), \\
& \widetilde{\widetilde{\mathrm{LSL}}}=\operatorname{TRFN}(31.80,32.05,34.05,35.65) .
\end{aligned}
$$

In this case, the type-2 fuzzy index (Eq. (1) shown in Box IV) indicates that when the specification limits are relaxed, the processes are re-diagnosed as capable unless the variance is large. When the process mean and process variance are unknown or non-crisp,
Table 1. Classification of quality conditions.

\begin{tabular}{lc}
\hline Quality condition & $C_{p p}$ \\
\hline Inadequate & $C_{p p}>100$ \\
Capable & $0.56<C_{p p}<1.00$ \\
Satisfactory & $0.44<C_{p p}<0.56$ \\
Excellent & $0.25<C_{p p}<0.44$ \\
Super & $C_{p p} \leq 0.25$ \\
\hline
\end{tabular}

the value of $\widetilde{\widetilde{C_{p p}^{\prime \prime}}}$ cannot be determined precisely. In the following, based on the relatively imprecise data for D1, a capability analysis will be carried out by assuming that the specification limits are type-2 fuzzy. The performance of the three fuzzy estimators $\widehat{C_{p p, B}^{\prime \prime} \text {, }}$ $\widetilde{\widetilde{C}} \widetilde{\widetilde{C}}$, and $\widetilde{C_{p p, A d f}^{\prime \prime \prime}}$ will be discussed. The simulation will be done via the computer language $R$, and the defuzzification will be conducted using the Total Integral Value (TIV) method [42].

Definition. Total Integral Value (TIV) method [42]: Let $A=[a, b, c, d]$ be a trapezoidal fuzzy number where $-\infty<a \leq b \leq c \leq d<\infty$.

The TIV for interval type-2 fuzzy sets with optimism $\alpha \in[0,1]$ is defined as $I_{T}^{\alpha}(A)=$ $\frac{1}{2}[\alpha(c+d)+(1-\alpha)(a+b)]$.

Theorem. The order of fuzzy incapability index is preserved by TIV method.

Proof. Let $A=[a, b, c, d]$ and $A^{\prime}=\left[a^{\prime}, b^{\prime}, c^{\prime}, d^{\prime}\right]$ be two trapezoidal fuzzy numbers where $-\infty<a \leq b \leq c \leq$ $d<\infty$ and $-\infty<a^{\prime} \leq b^{\prime} \leq c^{\prime} \leq d^{\prime}<\infty$.

When $A^{\prime}>A$, it can be implied that $a^{\prime}>d, a^{\prime}>$ $a, b^{\prime}>b, c^{\prime}>c$, and $d^{\prime}>d$. Hence:

$$
I_{T}^{\alpha}\left(A^{\prime}\right)-I_{T}^{\alpha}(A)=\frac{1}{2}\left[\alpha\left(c^{\prime}+d^{\prime}\right)+(1-\alpha)\left(a^{\prime}+b^{\prime}\right)\right]
$$

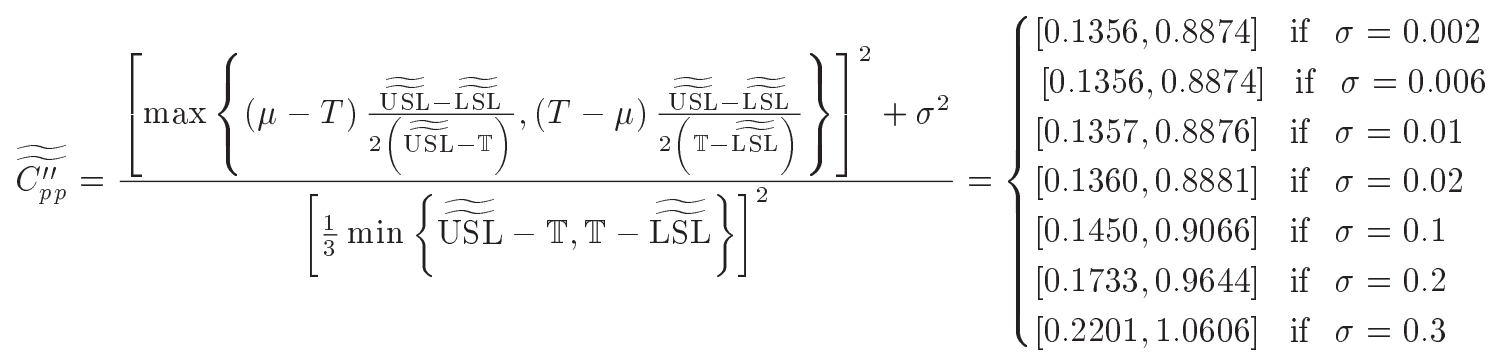




$$
\begin{aligned}
& -\frac{1}{2}[\alpha(c+d)+(1-\alpha)(a+b)] \\
& =\frac{1}{2}\left\{\alpha\left[\left(c^{\prime}+d^{\prime}\right)-(c+d)\right]+(1-\alpha)\left[\left(a^{\prime}+b^{\prime}\right)\right.\right. \\
& -(a+b)]\}=\frac{1}{2}\left\{\alpha\left[\left(c^{\prime}-c\right)+\left(d^{\prime}-d\right)\right]\right. \\
& \left.+(1-\alpha)\left[\left(a^{\prime}-a\right)+\left(b^{\prime}-b\right)\right]\right\}>0 .
\end{aligned}
$$

In other words, If $A^{\prime}>A$, then $I_{T}^{\alpha}\left(A^{\prime}\right)>I_{T}^{\alpha}(A)$, and therefore, the order of fuzzy incapability index is preserved by TIV.

Our concern about the TFT-LCD process quality is the distance D1 on the first layer. For convenience purposes, let us use $x$ to represent it instead. Usually, the continuous quantity "distance" is relatively imprecise due to such limitations as measurement equipment.
When sampled over time:

$$
\begin{aligned}
\widetilde{x_{1}}= & {\left[x_{1}^{L}, x_{1}^{R}\right], \widetilde{x_{2}}=\left[x_{2}^{L}, x_{2}^{R}\right], \ldots, \widetilde{x_{n}}=\left[x_{n}^{L}, x_{n}^{R}\right], } \\
& x_{i}^{L} \leq x_{i}^{R},
\end{aligned}
$$

can be $n$ fuzzy observations from a normal distribution $N\left(36.5865, \sigma^{2}\right)$. When $n$ increases from 10, 20, 50, 100, 200, 300 to 400 , the performances of $\widetilde{C_{p p, B}^{\prime \prime}, ~} \widetilde{C_{p p, N A}^{\prime \prime}}$,

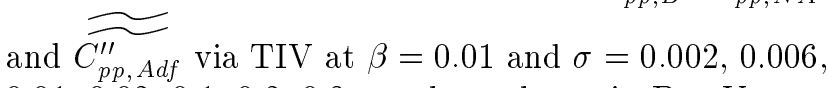
$0.01,0.02,0.1,0.2,0.3$ are those shown in Box V.

Remark 2. Due to the fuzziness of the data, $\widetilde{C_{p p, N A}^{\prime \prime}}$ may not be calculated if the sample size is below 21 .

\begin{tabular}{|c|c|}
\hline 10 & 100 \\
\hline$T I V \underset{C_{p p, B}^{\| \prime \prime}}{\widetilde{=}}=$ & $\left\{\begin{array}{l}0.58 \rightarrow 0.54 \rightarrow 0.53 \rightarrow 0.52 \rightarrow 0.52 \rightarrow 0.51 \rightarrow 0.51 \text { for } \sigma=0.002 \\
0.58 \rightarrow 0.54 \rightarrow 0.53 \rightarrow 0.52 \rightarrow 0.52 \rightarrow 0.51 \rightarrow 0.51 \text { for } \sigma=0.006 \\
0.58 \rightarrow 0.54 \rightarrow 0.53 \rightarrow 0.52 \rightarrow 0.52 \rightarrow 0.51 \rightarrow 0.51 \text { for } \sigma=0.01 \\
0.60 \rightarrow 0.55 \rightarrow 0.53 \rightarrow 0.52 \rightarrow 0.52 \rightarrow 0.52 \rightarrow 0.51 \text { for } \sigma=0.02 \\
0.83 \rightarrow 0.66 \rightarrow 0.59 \rightarrow 0.57 \rightarrow 0.55 \rightarrow 0.55 \rightarrow 0.55 \text { for } \sigma=0.1 \\
1.29 \rightarrow 0.87 \rightarrow 0.70 \rightarrow 0.65 \rightarrow 0.63 \rightarrow 0.61 \rightarrow 0.61 \text { for } \sigma=0.2 \\
1.93 \rightarrow 1.15 \rightarrow 0.87 \rightarrow 0.78 \rightarrow 0.73 \rightarrow 0.71 \rightarrow 0.71 \text { for } \sigma=0.3\end{array}\right.$ \\
\hline$T I V \underset{\widetilde{C_{p p, N A}^{\prime \prime}}}{\widetilde{C}}=$ & $\left\{\begin{array}{l}N a N \rightarrow N a N \rightarrow 0.53 \rightarrow 0.52 \rightarrow 0.51 \rightarrow 0.51 \rightarrow 0.51 \text { for } \sigma=0.002 \\
N a N \rightarrow N a N \rightarrow 0.53 \rightarrow 0.52 \rightarrow 0.52 \rightarrow 0.51 \rightarrow 0.51 \text { for } \sigma=0.006 \\
N a N \rightarrow N a N \rightarrow 0.53 \rightarrow 0.52 \rightarrow 0.52 \rightarrow 0.51 \rightarrow 0.51 \text { for } \sigma=0.01 \\
N a N \rightarrow N a N \rightarrow 0.53 \rightarrow 0.52 \rightarrow 0.52 \rightarrow 0.52 \rightarrow 0.51 \text { for } \sigma=0.02 \\
N a N \rightarrow 0.70 \rightarrow 0.59 \rightarrow 0.57 \rightarrow 0.55 \rightarrow 0.55 \rightarrow 0.55 \text { for } \sigma=0.1 \\
N a N \rightarrow 1.01 \rightarrow 0.71 \rightarrow 0.66 \rightarrow 0.62 \rightarrow 0.62 \rightarrow 0.61 \text { for } \sigma=0.2 \\
N a N \rightarrow 1.43 \rightarrow 0.89 \rightarrow 0.78 \rightarrow 0.74 \rightarrow 0.71 \rightarrow 0.71 \text { for } \sigma=0.3 .\end{array}\right.$ \\
\hline
\end{tabular}
This restriction was formerly stated in Section 4 when $\widetilde{\widetilde{C_{p p, N A}^{\prime \prime}}}$ was introduced TIV $\widetilde{C_{p p, A d f}^{\prime \prime}}$ is calculated by the equation shown in Box VI. When $n \geq 50$, for all $\sigma$ considered, the TIV falls within the range shown in Eq. (1) which represents the case when all the

Box V

$$
T I V \widetilde{\widetilde{C_{p p, A d f}^{\prime \prime}}}=\left\{\begin{array}{l}
0.56 \rightarrow 0.54 \rightarrow 0.52 \rightarrow 0.52 \rightarrow 0.52 \rightarrow 0.51 \rightarrow 0.51 \text { for } \sigma=0.002 \\
0.56 \rightarrow 0.54 \rightarrow 0.52 \rightarrow 0.52 \rightarrow 0.52 \rightarrow 0.51 \rightarrow 0.51 \text { for } \sigma=0.006 \\
0.57 \rightarrow 0.54 \rightarrow 0.53 \rightarrow 0.52 \rightarrow 0.52 \rightarrow 0.51 \rightarrow 0.51 \text { for } \sigma=0.01 \\
0.58 \rightarrow 0.55 \rightarrow 0.53 \rightarrow 0.52 \rightarrow 0.52 \rightarrow 0.52 \rightarrow 0.52 \text { for } \sigma=0.02 \\
0.76 \rightarrow 0.64 \rightarrow 0.59 \rightarrow 0.56 \rightarrow 0.55 \rightarrow 0.55 \rightarrow 0.55 \text { for } \sigma=0.1 \\
1.10 \rightarrow 0.84 \rightarrow 0.70 \rightarrow 0.66 \rightarrow 0.62 \rightarrow 0.61 \rightarrow 0.61 \text { for } \sigma=0.2 \\
1.61 \rightarrow 1.11 \rightarrow 0.85 \rightarrow 0.77 \rightarrow 0.73 \rightarrow 0.71 \rightarrow 0.71 \text { for } \sigma=0.3 .
\end{array}\right.
$$




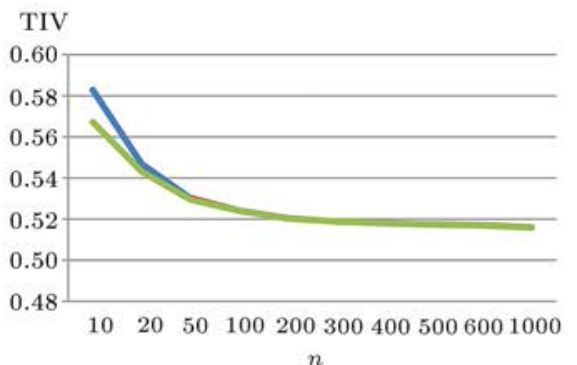

(a) $\sigma=0.002$

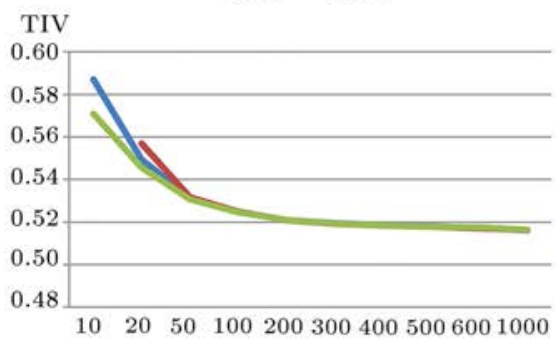

(c) $\sigma=0.01$

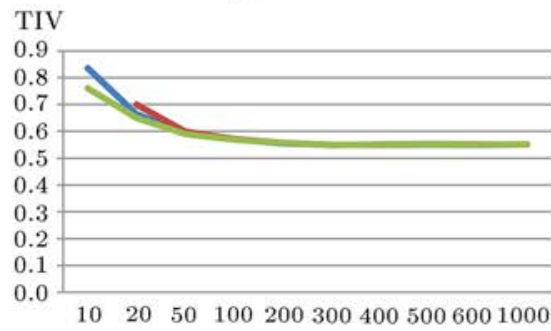
$n$

(e) $\sigma=0.1$

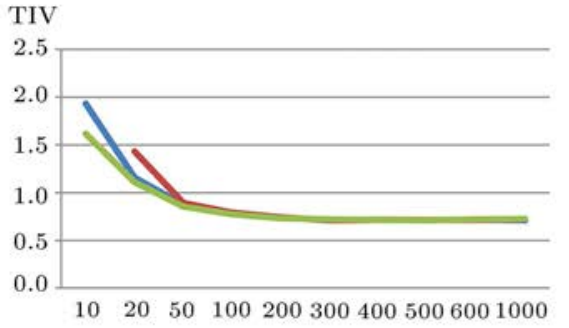

(g) $\sigma=0.3$

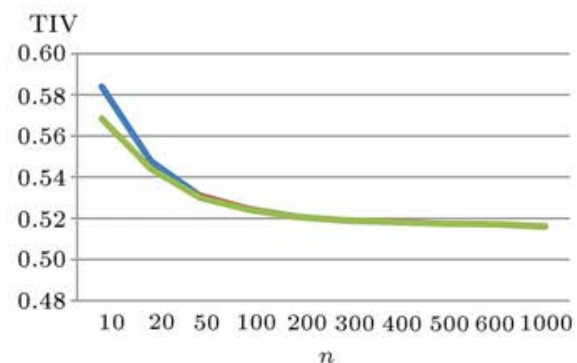

(b) $\sigma=0.006$

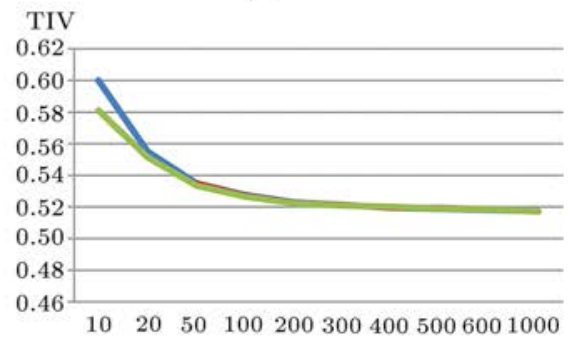

(d) $\sigma=0.02$

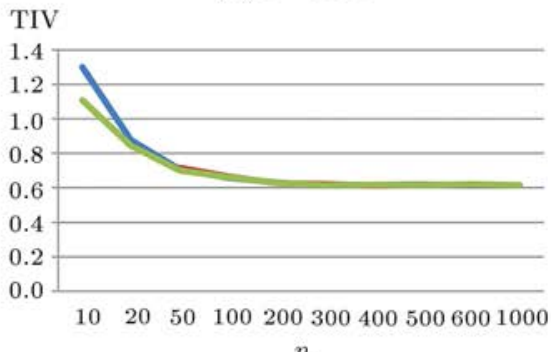

(f) $\sigma=0.2$

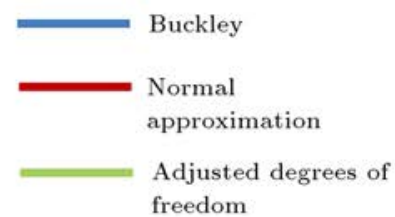

Figure 4. Total Integral Value (TIV) as a function of $n$ for different standard deviations.

Table 2. The limit of Total Integral Value (TIV) as $n=300$ for all the three methods (numbers given in the parentheses are the values of index for crisp case).

\begin{tabular}{cccccccc}
\hline $\boldsymbol{\sigma}$ & 0.002 & 0.006 & 0.01 & 0.02 & 0.1 & 0.2 & 0.3 \\
TIV & $0.51(1.2541)$ & $0.51(1.2543)$ & $0.51(1.2549)$ & $0.51(1.2574)$ & $0.55(1.3375)$ & $0.61(1.5885)$ & $0.71(2.0065)$ \\
\hline
\end{tabular}

parameters are known. When the process variance is small, i.e., $\sigma=0.002,0.006,0.01,0.02,0.1$, all the three estimating methods provide TIVs that fall within the range, even for the sample size of 10 .

As shown in Figure 4, the graph of TIV drops rapidly at the beginning, but slowly later as $n$ increases. The decreasing rate for the TIV becomes insignificant when the sample size is greater than 100. Overall, the TIVs for all three methods converge when the sample size reaches 300 (see Table 2). Compared to a case when the specification limits are crisp, the TIV yields a completely opposite conclusion about the process quality.

Parts (a)-(c) of Figures 5-7 show the membership 


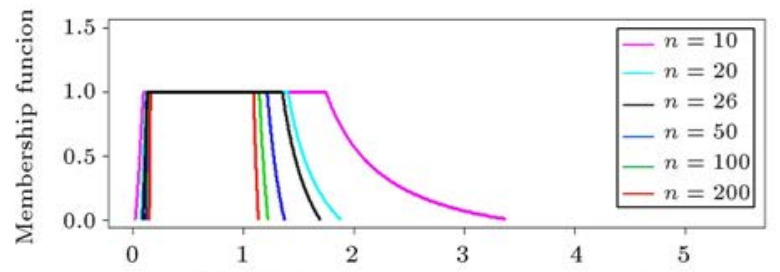

(a) $C_{p p}^{\prime \prime}$ (Buckley, different $n, \sigma=0.2$ )

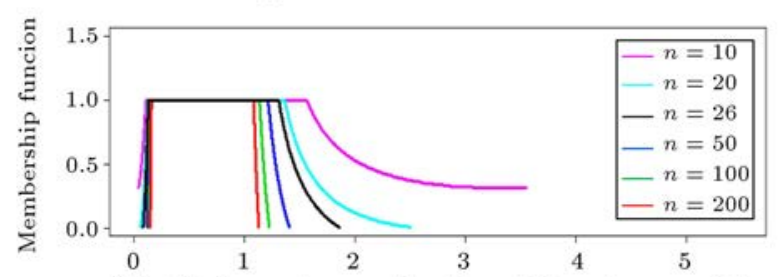

(b) $C_{p p}^{\prime \prime}$ (normal approximation, different $n, \sigma=0.2$ )

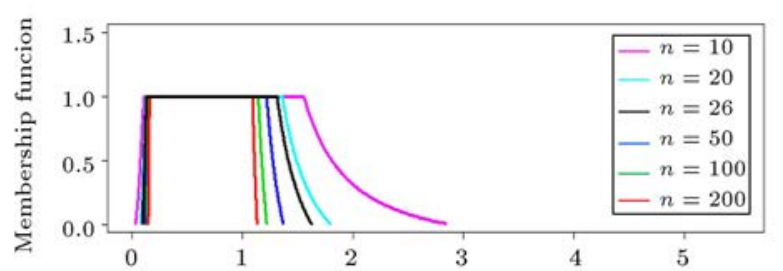

(c) $C_{p p}^{\prime \prime}$ (Adjusted degrees of freedom, different $n, \sigma=0.2$ )

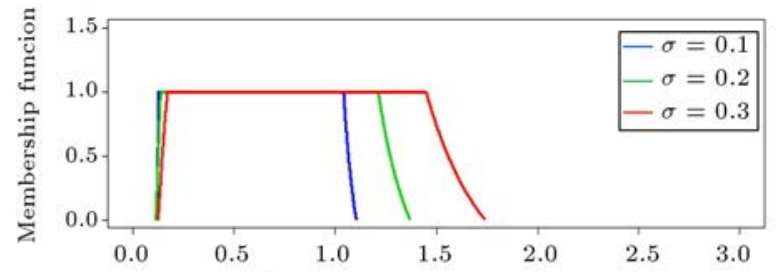

(d) $C_{p p}^{\prime \prime}$ (Buckley, different $\sigma, n=50$ )

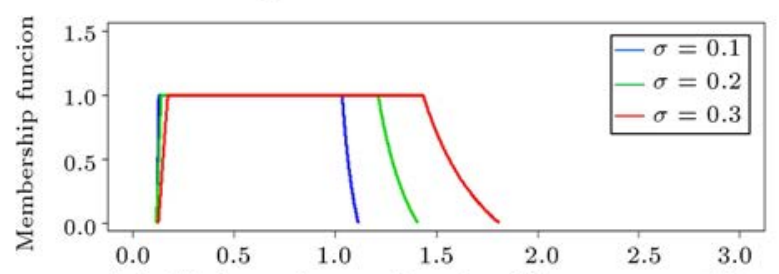

(e) $C_{p p}^{\prime \prime}$ (normal approximation, different $\sigma, n=50$ )

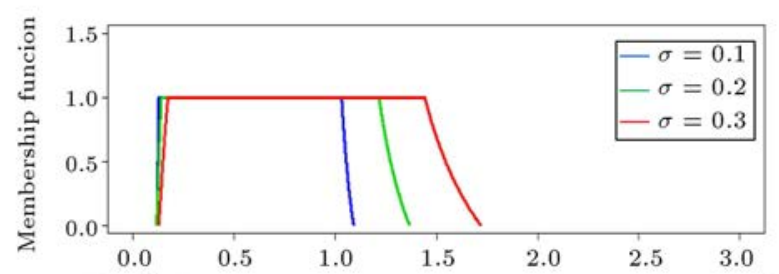

(f) $C_{p p}^{\prime \prime}$ (adjusted degrees of freedom, different $\sigma, n=50$ )

Figure 5. Membership functions of fuzzy estimators when $\beta=0.01$.

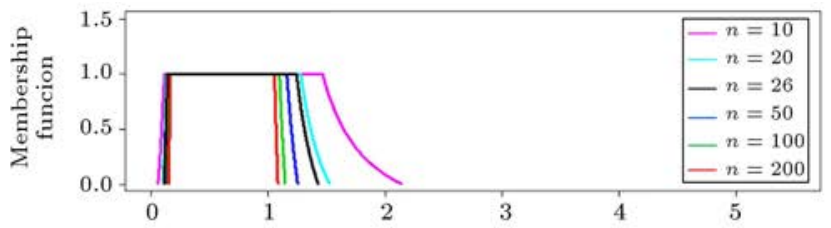

(a) $C_{p p}^{\prime \prime}$ (Buckley, different $n, \sigma=0.2$ )

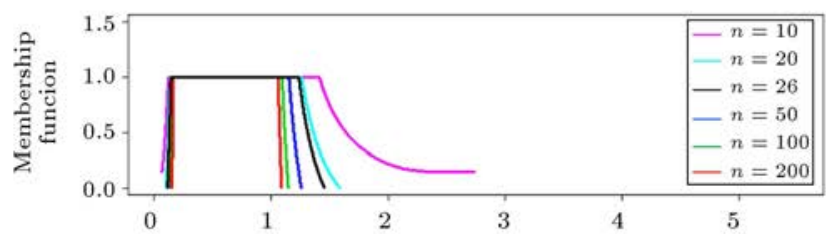

(b) $C_{p p}^{\prime \prime}$ (normal approximation, different $n, \sigma=0.2$ )

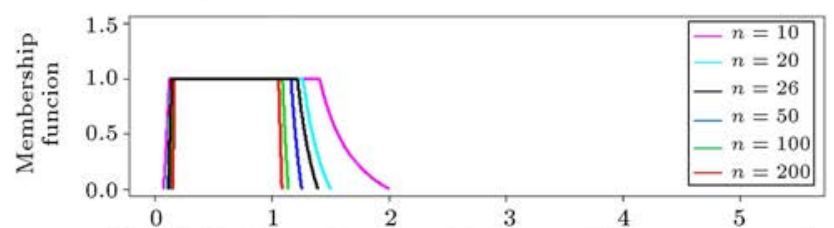

(c) $C_{p p}^{\prime \prime}$ (Adjusted degrees of freedom, different $n, \sigma=0.2$ )

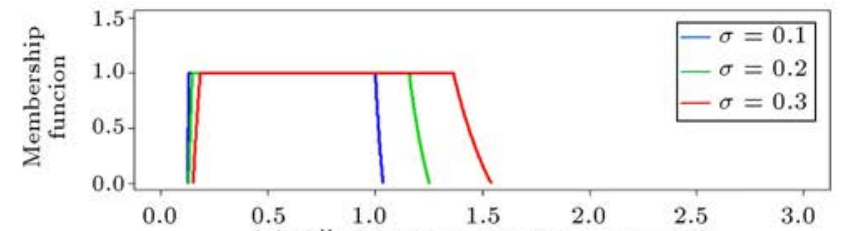

(d) $C_{p p}^{\prime \prime}$ (Buckley, different $\sigma, n=50$ )

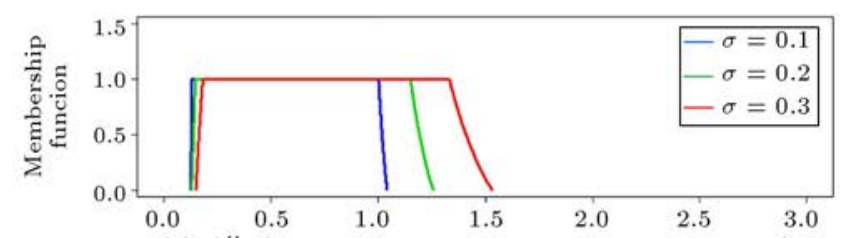

(e) $C_{p p}^{\prime \prime}$ (normal approximation, different $\sigma, n=50$ )

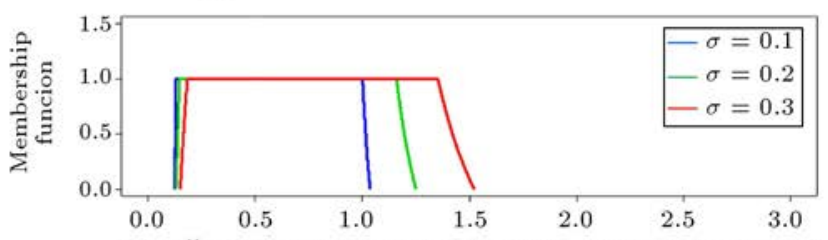

(f) $C_{p p}^{\prime \prime}$ (adjusted degrees of freedom, different $\sigma, n=50$ )

Figure 6. Membership functions of fuzzy estimators when $\beta=0.05$.

functions of the estimators when $\sigma=0.2$ and $\beta=0.01$, $0.05,0.1$. It is interesting that when the confidence level $1-\beta$ decreases, the value of the estimated incapability index also decreases, meaning that the quality is enhanced. In addition, when the standard deviation remains fixed, the sample size has the least

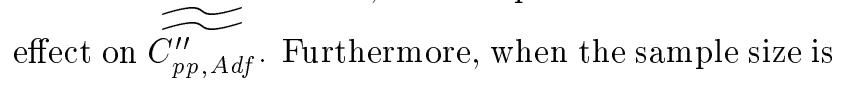

fixed, the standard deviation has similar effect on the three estimators (see Parts (d)-(f) of Figures 5-7).

Figure 8 points to a case characterized by $\sigma=$ 0.006 and $\beta=0.01$. The pattern is similar to that with larger variance, except that the TIV is relatively small. Once again, the standard deviation does not have much impact on the membership functions. 


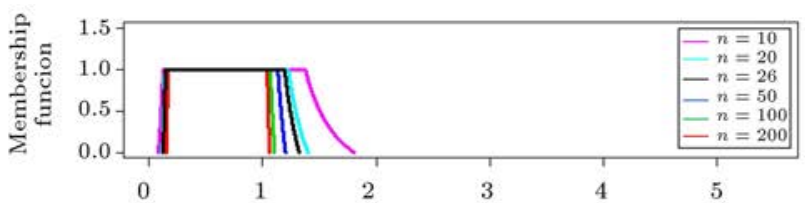

(a) $C_{p p}^{\prime \prime}$ (Buckley, different $n, \sigma=0.2$ )

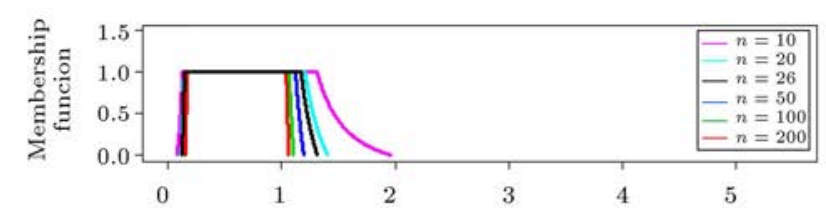

(b) $C_{p p}^{\prime \prime}$ (normal approximation, different $n, \sigma=0.2$ )

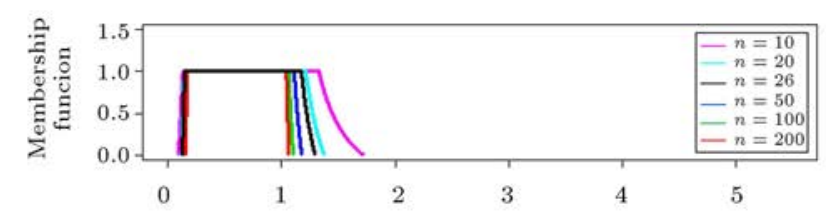

(c) $C_{p p}^{\prime \prime}$ (Adjusted degrees of freedom, different $n, \sigma=0.2$ )

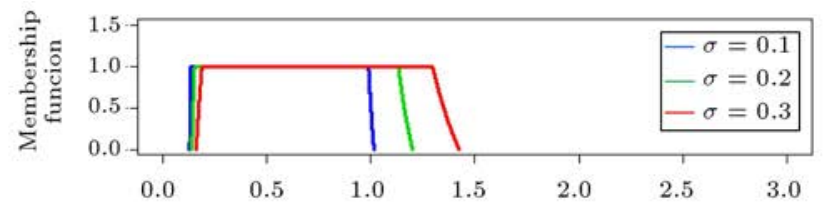

(d) $C_{p p}^{\prime \prime}$ (Buckley, different $\sigma, n=50$ )

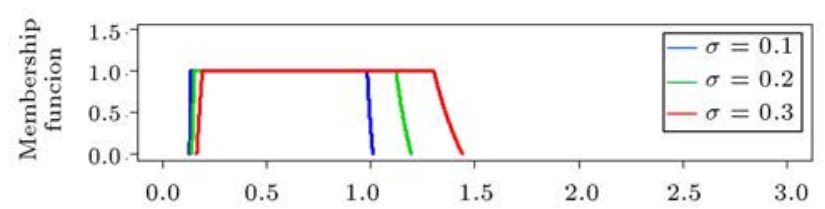

(e) $C_{p p}^{\prime \prime}$ (normal approximation, different $\sigma, n=50$ )

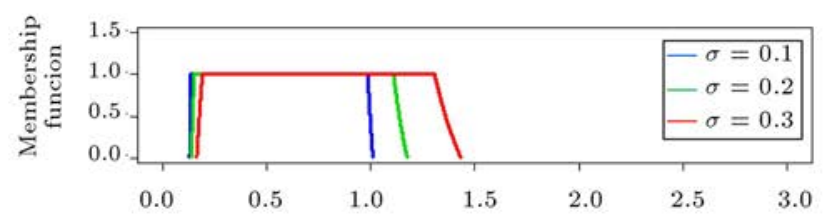

(f) $C_{p p}^{\prime \prime}$ (adjusted degrees of freedom, different $\sigma, n=50$ )

Figure 7. Membership functions of fuzzy estimators when $\beta=0.1$.

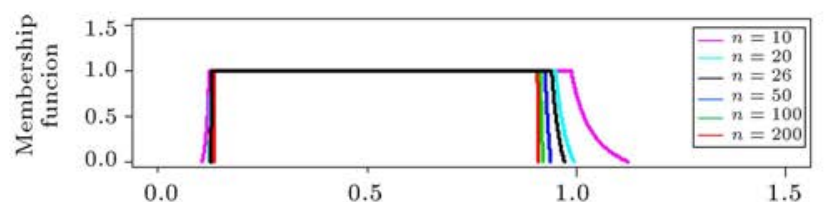

(a) $C_{p p}^{\prime \prime}$ (Buckley, different $n, \sigma=0.006$ )

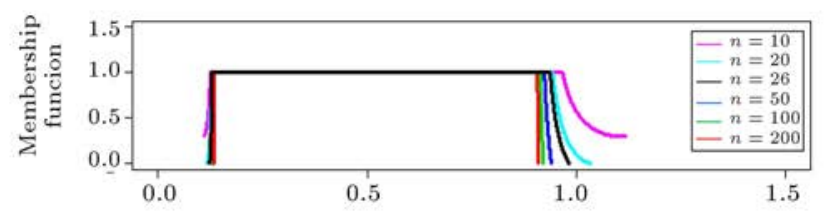

(b) $C_{p p}^{\prime \prime}$ (normal approximation, different $n, \sigma=0.006$ )

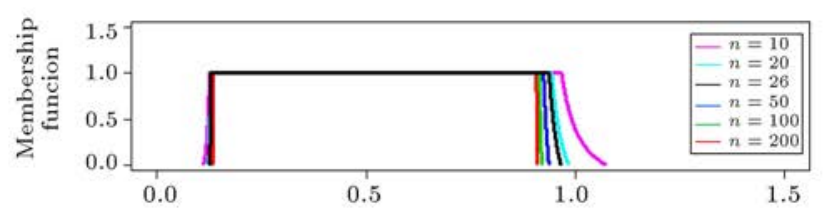

(c) $C_{p p}^{\prime \prime}$ (adjusted degrees of freedom, different $n, \sigma=0.006$ )

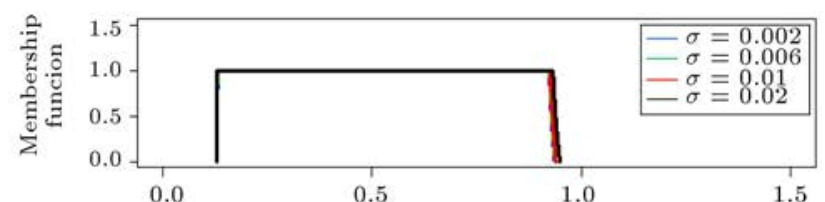

(d) $C_{p p}^{\prime \prime}$ (Buckley, different $\sigma, n=50$ )

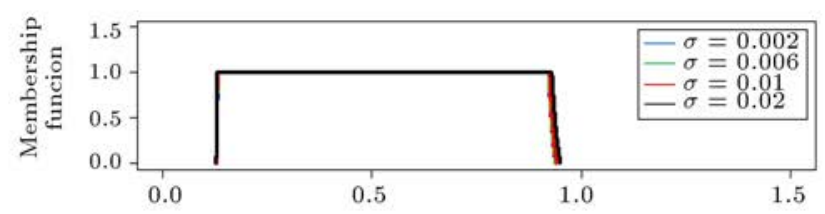

(e) $C_{p p}^{\prime \prime}$ (normal approximation, different $\sigma, n=50$ )

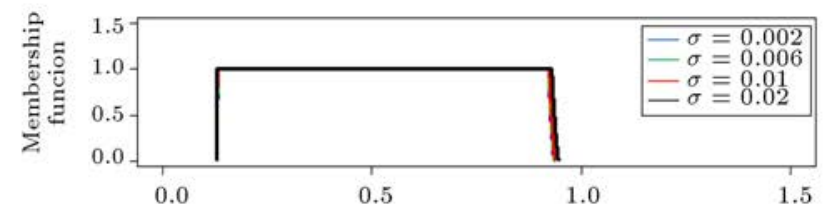

(f) $C_{p p}^{\prime \prime}$ (adjusted degrees of freedom, different $\sigma, n=50$ )

Figure 8. Membership functions with $\beta=0.01$ and $\sigma=0.002,0.006,0.01,0.02$.

\section{Discussion and conclusions}

Usually, the process is diagnosed as incapable if the related measurements fall outside the specification limits. In order to increase the process yield, engineers may modify the specification limits. In this article, as a function of process mean, variance, and type- 2 fuzzy specification limits, the fuzzy type- 2 incapability index $\widetilde{\widetilde{C_{p p}^{\prime \prime}}}$ is proposed. In reality, process mean and process variance are hardly known precisely which cause difficulty in computing $\widetilde{\widehat{C_{p p}^{\prime \prime}}}$. Based on fuzzy data, three fuzzy estimators $\widetilde{\widetilde{C_{p p, B}^{\prime \prime}}}, \widetilde{\widetilde{C_{p p, N A}^{\prime \prime}}}$, and $\widetilde{\widetilde{C_{p p, A d f}^{\prime \prime}}}$ of $\widetilde{\widetilde{C_{p p}^{\prime \prime}}}$ are considered.

A simulation study shows that minimal sample 


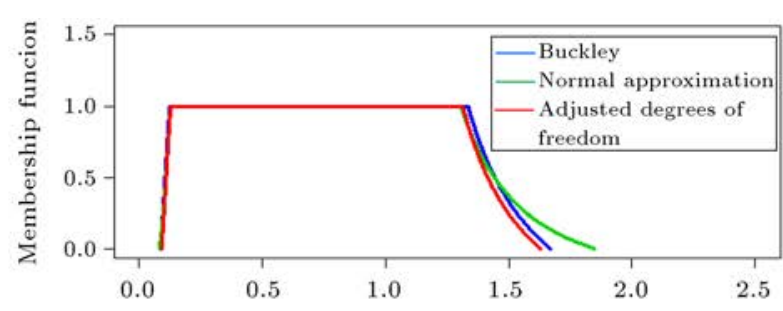

(a) $C_{p p}^{\prime \prime}$ (different methods, $\sigma=0.2, n=26$ )

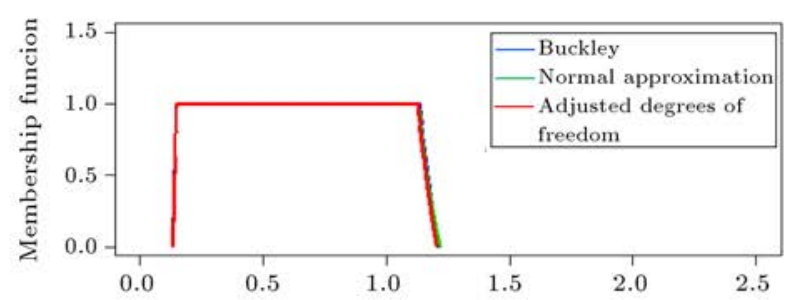

(c) $C_{p p}^{\prime \prime}$ (different methods, $\sigma=0.2, n=100$ )

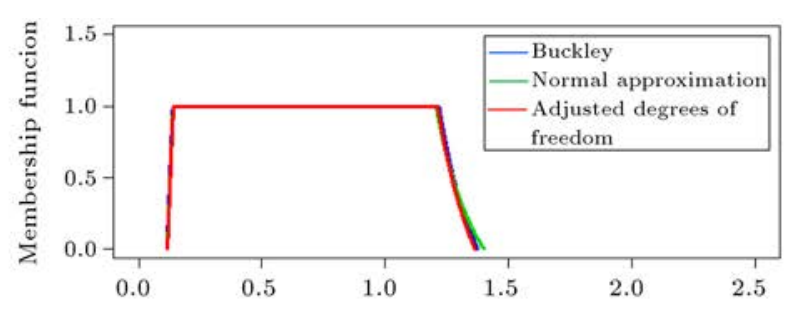

(b) $C_{p p}^{\prime \prime}$ (different methods, $\sigma=0.2, n=50$ )

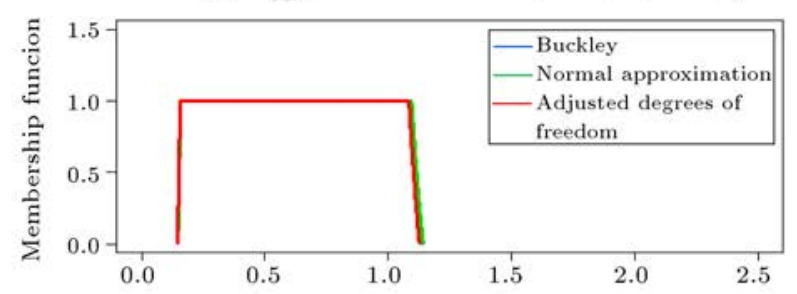

(d) $C_{p p}^{\prime \prime}$ (different methods, $\sigma=0.2, n=200$ )

Figure 9. Membership function for three estimators when $\beta=0.01, \sigma=0.2$, and $n=26,50,100,200$.

size 25 is required to make the normal approximation approach applicable to computing the estimator $\widetilde{\mathrm{C}^{\prime \prime} \text { pp,NA. }}$. The Total Integral Value (TIV) of $\widetilde{\widetilde{C_{p p, B}^{\prime \prime}}}$,

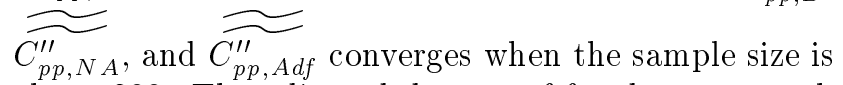
above 300 . The adjusted degrees of freedom approach to variance estimation suitable for a wide range of distributions implies that the performance of $\widetilde{C_{p p, A d f}^{\prime \prime}}$ may be more conservative than the other two estimators. On the other hand, the degrees of freedom of the adjusted method are equal to those of the classical chi-square under normality and the behavior of $\widetilde{C_{p p, A d f}^{\prime \prime}}$ should be very close to that of $\widetilde{\widetilde{C_{p p, B}^{\prime \prime}}}$ under normality at least for a large sample. Figure 9 shows the membership function of the three estimators when $\sigma=0.2$.

According to the simulation results, the effect of sample size is significant on the estimation, but the effect of the process variance is relatively insignificant, especially when the sample size is large. It is interesting to ask if a manufacturer should adopt an algorithm that yields much higher precision, which comes at the expense of paying much higher prices.

The estimators proposed for the fuzzy incapability index $\widetilde{\widetilde{C_{p p}^{\prime \prime}}}$ are based on fuzzy normal data, and one needs to verify the normality of fuzzy numbers used in our discussions. Since we are dealing with interval fuzzy numbers, only the end points are used in the estimating procedure. Therefore, checking the normality of end points will be sufficient. Let $\left[X_{1}^{L}, X_{1}^{R}\right],\left[X_{2}^{L}, X_{2}^{R}\right], \ldots,\left[X_{n}^{L}, X_{n}^{R}\right], X_{i}^{L} \leq X_{i}^{R}, i=$ $1,2, \ldots, n$ denote an interval fuzzy random sample; the normality of $X_{1}^{L}, \ldots, X_{n}^{L}$, or $X_{1}^{R}, \ldots, X_{n}^{R}$, can be tested by the traditional Shapiro-Wilk test. We will treat
$X_{1}^{L}, \ldots, X_{n}^{L}$, or $X_{1}^{R}, \ldots, X_{n}^{R}$, as normally distributed if the normality test cannot be rejected. However, if the normality test is rejected, then the distribution of $\frac{\bar{X}-\mu}{s / \sqrt{n}}$ will not be t-distribution. In this case, our analysis of $\widetilde{\widetilde{C_{p p, B}^{\prime \prime}}}$ needs some modifications. According to the Central Limit theorem and Slutsky's theorem, $\frac{\bar{X}-\mu}{s / \sqrt{n}}$ will be normally distributed approximately when sample size is large enough. Consequently, our analysis is still valid when normal quantile $z$ replaces $t$ quantile. Take the Thin-Film-Transistor Liquid-Crystal Display (TFT-LCD) given in Section 5 as the example. Suppose the distance D1 between L1 and L2 on the first layer is measured unit by unit over a period of time; then, the plot of D1 will make it appear as a bellshaped fuzzy number. Table 3 lists the partial data of D1. The $p$-value obtained by Shapiro-Wilk test is larger than 0.1 on both end points and is higher than the ordinary level of significance. Hence, there is no significant evidence to reject the hypothesis that both $X_{i}^{L}$ and $X_{i}^{R}$ follow normal distributions at Level 0.1 . The Q-Q plot is shown in Figure 10(a)-(c) and the histogram with a fitting normal curve is shown in Figure 10(b)-(d).

Another question that is very practical in real life is "how flexible should the specification limits be to optimize the company profit?". For instance, suppose that the specification limits are extended outward symmetrically $k . \sigma$ from the crisp specification limits $\left(l_{2}, l_{3}\right)$, say $u_{1}=l_{2}-3 k \cdot \sigma, l_{1}=l_{2}-2 k \cdot \sigma, u_{2}=l_{2}-k \cdot \sigma$, $u_{3}=l_{3}+k \cdot \sigma, l_{4}=l_{3}+2 k \cdot \sigma$, and $u_{4}=l_{3}+3 k \cdot \sigma$ (see Figure 1); then, when $n=100, \sigma=0.2, \beta=0.01$, the conclusion about the quality of a production line will reverse when $k$ increases, as shown in Table 4 . For those $k$ 's where $k . \sigma$ away from the crisp specification limits is acceptable, in order to maintain the reputation 
Table 3. Fuzzy data from the simulation.

\begin{tabular}{ccccccccccc}
\hline $\boldsymbol{n}$ & $\mathbf{1}$ & $\mathbf{2}$ & $\mathbf{3}$ & $\mathbf{4}$ & $\mathbf{5}$ & $\mathbf{6}$ & $\mathbf{7}$ & $\mathbf{8}$ & $\mathbf{9}$ & $\mathbf{1 0}$ \\
\hline $\mathrm{x}_{\boldsymbol{i}}^{L}$ & 36.5826 & 36.5825 & 36.5832 & 36.5873 & 36.5853 & 36.5713 & 36.5816 & 36.5737 & 36.5837 & 36.5772 \\
$x_{i}^{R}$ & 36.5874 & 36.5876 & 36.5872 & 36.5893 & 36.5903 & 36.5981 & 36.5908 & 36.5996 & 36.5863 & 36.5979 \\
\hline $\boldsymbol{n}$ & $\mathbf{1 1}$ & $\mathbf{1 2}$ & $\mathbf{1 3}$ & $\mathbf{1 4}$ & $\mathbf{1 5}$ & $\mathbf{1 6}$ & $\mathbf{1 7}$ & $\mathbf{1 8}$ & $\mathbf{1 9}$ & $\mathbf{2 0}$ \\
\hline$x_{\boldsymbol{i}}^{L}$ & 36.5850 & 36.5892 & 36.5775 & 36.5838 & 36.5873 & 36.5745 & 36.5813 & 36.5803 & 36.5764 & 36.5798 \\
$x_{i}^{R}$ & 36.5865 & 36.5904 & 36.5948 & 36.5907 & 36.5891 & 36.5919 & 36.5890 & 36.5972 & 36.5950 & 36.5974 \\
\hline $\boldsymbol{n}$ & $\mathbf{2 1}$ & $\mathbf{2 2}$ & $\mathbf{2 3}$ & $\mathbf{2 4}$ & $\mathbf{2 5}$ & $\mathbf{2 6}$ & $\mathbf{2 7}$ & $\mathbf{2 8}$ & $\mathbf{2 9}$ & $\mathbf{3 0}$ \\
\hline$x_{\boldsymbol{i}}^{L}$ & 36.5863 & 36.5825 & 36.5705 & 36.5812 & 36.5850 & 36.5783 & 36.5788 & 36.5754 & 36.5815 & 36.5752 \\
$x_{\boldsymbol{i}}^{R}$ & 36.5902 & 36.5902 & 36.5992 & 36.5951 & 36.5885 & 36.5870 & 36.5939 & 36.6011 & 36.5936 & 36.5999 \\
\hline
\end{tabular}

Table 4. Total Integral Value (TIV) for three estimators when $n=100, \sigma=0.2, \beta=0.01$ after extending the specification limits symmetrically outward from the crisp limits.

\begin{tabular}{ccccccccccc}
\hline $\boldsymbol{k}$ & $\mathbf{1}$ & $\mathbf{2}$ & $\mathbf{3}$ & $\mathbf{4}$ & $\mathbf{5}$ & $\mathbf{6}$ & $\mathbf{7}$ & $\mathbf{8}$ & $\mathbf{9}$ & $\mathbf{1 0}$ \\
\hline$\widetilde{C_{p p, B}^{\prime \prime}}$ & 6.2879 & 4.1941 & 3.0939 & 2.4041 & 1.9355 & 1.5820 & 1.3243 & 1.1284 & 0.9649 & 0.8339 \\
$\widetilde{\widetilde{C_{p p, N A}^{\prime \prime}}}$ & 6.4095 & 4.2202 & 3.0977 & 2.3960 & 1.9318 & 1.5953 & 1.3228 & 1.1334 & 0.9803 & 0.8480 \\
$\widetilde{\widetilde{C_{p p, A d f}^{\prime \prime}}}$ & 6.3357 & 4.1947 & 3.1004 & 2.4148 & 1.9173 & 1.5824 & 1.3315 & 1.1182 & 0.9691 & 0.8348 \\
\hline
\end{tabular}

of a company, the degree of modification $k$ must be determined wisely and cautiously.

In conclusion, based on the type-2 fuzzy incapability index, a process may be categorized as capable with-

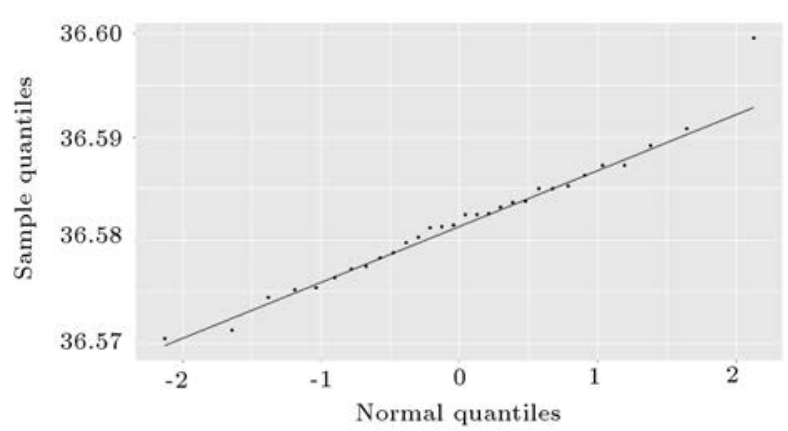

(a) Q-Q plot for left end points

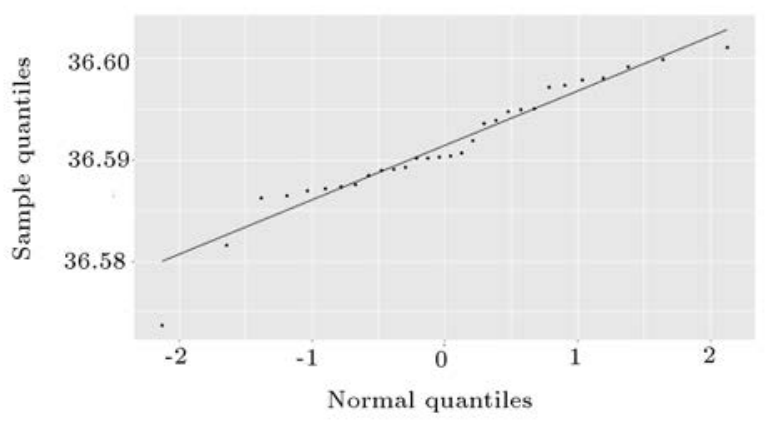

(c) Q-Q plot for right end points out ruining the whole system if the quality specification limits are chosen properly. However, it is better to keep the process variance in mind to avoid other possible problems. Currently, there are neither theoretical rules

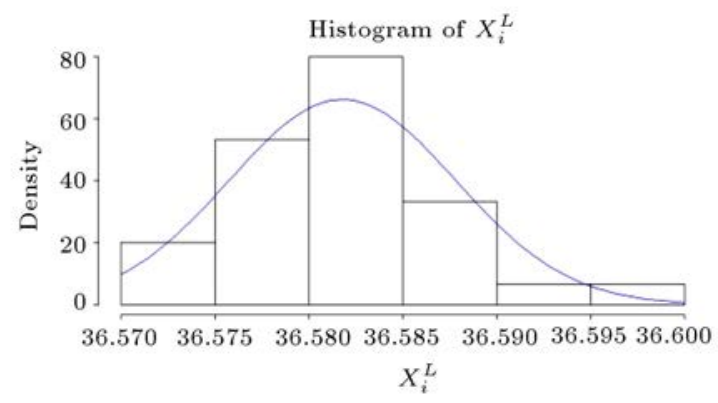

(b) Histogram for left end points

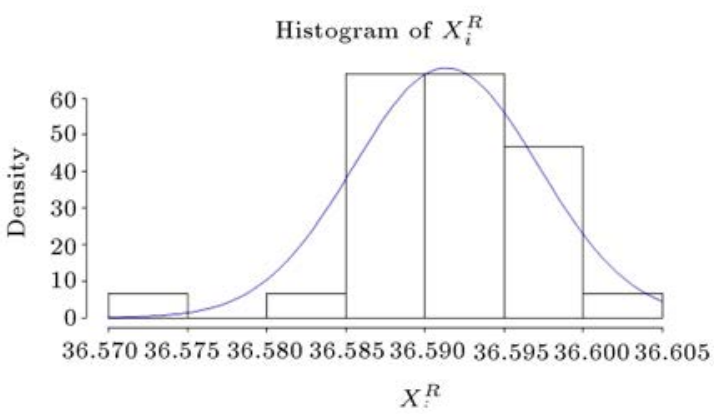

(d) Histogram for right end points

Figure 10. Q-Q plot and histogram for end points. 
nor superior strategies to follow how to determine the fuzzy specification limits; therefore, trial and error is a widely used approach by engineers. At last, the current research is focused on the characteristics of quality that follow a normal distribution and for future research, investigating the non-normal case will be our priority.

\section{Acknowledgement}

The authors would like to thank anonymous referees for their helpful comments, which improved the presentation of this paper.

\section{References}

1. Zadeh, L.A. "Fuzzy sets", Information and Control, 8, pp. 338-353 (1965).

2. Black, M. "Vagueness: An exercise in logical analysis", Philosophy of Science, 4, pp. 427-455 (1937).

3. Rabieha, M., Modarresb, M., and Azar, A. "Robustfuzzy model for supplier selection under uncertainty: An application to the automobile industry", Scientia Iranica, E, 25(4), pp. 2297-2311 (2018).

4. Kane, V.E. "Process capability indices", J. Quality Technology, 18, pp. 41-52 (1986).

5. Chan, L.K., Cheng, S.W., and Spiring, F.A. "A new measure of process capability", Journal of Quality Technology, 20(3), pp. 162-175 (1988).

6. Pearn, W.L., Kotz, S., and Johnson, N.L. "Distribution and inferential properties of capability indices", Journal of Quality Technology, 24, pp. 216-231 (1992).

7. Vanman, K. "A unified approach to the capability indices", Statistica Sinica, 5, pp. 805-820 (1995).

8. Greenwich, M. and Jahr-Schaffrath, B.L. "A process incapability index", International Journal of Quality Reliability Management, 12, pp. 58-71 (1995).

9. Chen, K.S. "Incapability index with asymmetric tolerances", Statistica Sinica, 8, pp. 253-262 (1998).

10. Zadeh, L.A. "The concept of a linguistic variable and its application to approximate reasoning", Information Sciences, Part I, 8, pp. 199-249; Part II, 8, pp. 301357 (1975).

11. Parchami, A., Onar, S.C., Öztaysi, B., and Kahraman, C. "Process capability analysis using interval type-2 fuzzy sets", International Journal of Computational Intelligence Systems, 10, pp. 721-733 (2017).

12. Parchami, A., Mashinchi, M., Yavari, A.R., et al. "Process capability indices as fuzzy numbers", Austrian Journal of Statistics, 34(4), pp. 391-402 (2005a).

13. Parchami, A., Mashinchi, M., and Maleki, H.R. "Confidence interval for fuzzy process capability index", Transaction on System, 4(5), pp. 546-551 (2005b).

14. Moeti, M.T., Parchami, A., and Mashinchi, M. "A note on fuzzy process capability indices", Scientia Iranica, 13(4), pp. 379-385 (2006).
15. Parchami, A., Mashinchi, M., and Nia, P. "A consistent confidence interval for fuzzy capability index", Appl. Comput. Math, 7(1), pp. 143-161 (2008).

16. Parchami, A. and Mashinchi, M. "Testing the capability of fuzzy processes", Quality Technology \& Quantitative Management, 6(2), pp. 125-136 (2009).

17. Wu, C.W. "Decision-making in testing process performance with fuzzy data", European Journal of Operational Research, 193, pp. 499-509 (2009).

18. Hsu, B.M., Chiang, C.Y., and Shu, M.H. "Supplier selection using fuzzy quality data and their applications to touch screen", Expert Systems with Application, 37, pp. 6192-6200 (2010).

19. Chen, C.C., Lai, C.M., and Nien, H.Y. "Measuring process capability index with fuzzy data", Qua.l Quant, 44, pp. 529-535 (2010).

20. Wu, C.W. and Liao, M.Y. "Measuring process yield by fuzzy lower confidence bounds", 2010 International Symposium on Computer, Communication, Control and Automation, pp. 103-106 (2010).

21. Abdolshah, M., Yusuff, R.M., Hong, T.S., et al. "Measuring process capability index $C_{p m k}$ with fuzzy data and compare it with other fuzzy process capability indices", Expert Systems with Applications, 38, pp. 6452-6457 (2011).

22. Abdolshah, M. "Fuzzy process capability indices: A review", World Applied Sciences Journal, 16(12), pp. 1734-1740 (2012).

23. Yen, C.H. "Fuzzy testing for one-sided process capability indices", Communications in Statistics-Theory and Methods, 41, pp. 1603-1616 (2012).

24. Parchami, A., Sadeghpoour-Gildeh, B., Nourbakhsh, M., et al. "A new generation of process capability indices based on fuzzy measurements", Journal of Applied Statistics, 41(5), pp. 1122-1136 (2014).

25. Basu, S., Dan, P.K., and Thakur, A. "Experimental design in soap manufacturing foroptimization of fuzzified process capability index", Journal of Manufacturing Systems, 33, pp. 323-334 (2014).

26. Fayyaz, S., Ebrahimi, M., and Devin, A.G. "Fuzzy multivariate process capability index for measuring process capability", Shiraz Journal of System Management, 2(4)(8), pp. 41-56 (2014).

27. Abdolshah, M. "Measuring loss-based process capability index $L_{e}$ and Its Generation $L_{e}^{\prime \prime}$ with fuzzy numbers", Hindawi Publishing Corporation, Mathematical Problems in Engineering, Article ID 217406, pp. 1-8 (2015).

28. Geng, A., Wang, Z., Peng, C., and Han, Y. "A new fuzzy process capability estimation method based on kernel function and FAHP", IEEE Tranactions on Engineering Management, 63(2), pp. 177-188 (2016).

29. Kaya, I. "An overview of the fuzzy sets on process capability analysis", 10th Research /Expert Conference with International Participations, Quality 2017, Neum, B\&H, May, pp. 17-20 (2017). 
30. Kaya, I. and Baraçli, H. "Fuzzy process incapability index with asymmetric tolerances", J. of Multiple Valued Logic \& Soft Computing, 18, pp. 493-511 (2012).

31. Kaya, I. "The process incapability index under fuzziness with an application for decision making", International Journal of Computational Intelligence Systems, 7(1), pp. 114-128 (2014).

32. Abbasi, Z. and Sadeghpour Gildeh, B. "Assessing process performance with incapability index based on fuzzy critical value", Iranian Journal of Fuzzy Systems, 13(5), pp. 21-34 (2016).

33. Viertl, R. "On the description and analysis of measurements of continuous quantities", Kybernetika, 38(3), pp. 353-362 (2002).

34. Filzmoser, P. and Viertl, R. "Testing hypotheses with fuzzy data: the fuzzy p-value", Metrika, 59, pp. 21-29 (2004).

35. Puri, M.L. and Ralescu, D.A. "The concept of normality for fuzzy random variables", The Annals of Probability, 13(4), pp. 1373-1379 (1985).

36. Kaya, I. and Kahraman, C. "Fuzzy process capability analyses with fuzzy normal distribution", Expert Systems with Applications, 37, pp. 5390-5403 (2010).

37. Buckley, J.J., Fuzzy Probability and Statistics, Springer (2006).

38. Serfling, R.J., Approximation Theorems of Mathematical Statistics, John Wiley \& Sons (1980).

39. Hummel, R., Banga, S., and Hettmansperger, T.P., Better Confidence Intervals for the Variance in a Random Sample, courses.wcupa.edu/rbove/eco252/ OneVariance.pdf (2005).

40. Park, S.H., Lee, J.H. and Pahk, H.J. "In-line critical dimension measurement system development of LCD pattern proposed by newly developed edge detection algorithm", Journal of the Optical Society of Korea, October, 17(5), pp. 392-398 (2013).

41. Chen, K.S. and Chen, T.W. "Multi-process capability plot and fuzzy inference evaluation", International Journal of Production Economics, 111(1), pp. 70-79 (2008).

42. Lion, T.S. and Wang, M.J.J. "Ranking fuzzy numbers with integral value", Fuzzy Sets and Systems, 50, pp. 247-255 (1992).

\section{Biographies}

Sy-Mien Chen received her $\mathrm{PhD}$ from the Department of Mathematics, University of Maryland at College Park in 1990. She is currently an Associate Professor at Department of Mathematics, Fu-Jen Catholic University, Taiwan. Her research interests are statistics and statistical quality control. Her papers are mainly published at Statistics, Journal of Nonparametric Statistics, Communication in Statistics, Fu-Jen Studies.

Tzu-Ming Hung received his MS degree from Department of Electrical Engineering, I-Shou University, Kaohsiung City, Taiwan in 2010 and MS degree from Department of Mathematics, Fu-Jen Catholic University, New Taipei City, Taiwan in 2019. He is currently a Mathematics Teacher at Providence Girls' High School, New Taipei City, Taiwan. He was a process quality engineer in Chi Mei Optoelectronics Corporation. His research interests are control and statistical quality control. 